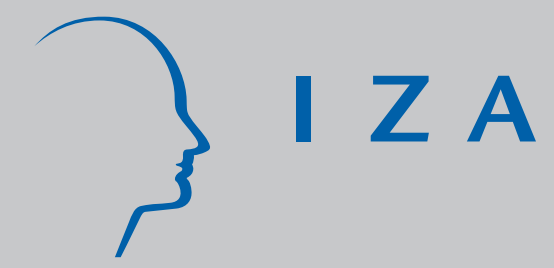

IZA DP No. 374

Counseling and Monitoring of Unemployed Workers: Theory and Evidence from a Controlled Social Experiment

Gerard J . van den Berg

Bas van der Klaauw

October 2001 


\title{
Counseling and Monitoring of Unemployed Workers: Theory and Evidence from a Controlled Social Experiment
}

\author{
Gerard J. van den Berg \\ Free University Amsterdam, Tinbergen Institute, IFAU-Uppsala, \\ CEPR and IZA, Bonn \\ Bas van der Klaauw \\ Free University Amsterdam
}

Discussion Paper No. 374

October 2001

\author{
IZA \\ P.O. Box 7240 \\ D-53072 Bonn \\ Germany \\ Tel.: +49-228-3894-0 \\ Fax: +49-228-3894-210 \\ Email: iza@iza.org
}

This paper can be downloaded without charge at:

http://papers.ssrn.com/abstract=xxxxxx

An index to IZA Discussion Papers is located at:

http://www.iza.org/publications/dps/

This Discussion Paper is issued within the framework of IZA's research area Project Evaluation. Any opinions expressed here are those of the author(s) and not those of the institute. Research disseminated by IZA may include views on policy, but the institute itself takes no institutional policy positions.

The Institute for the Study of Labor (IZA) in Bonn is a local and virtual international research center and a place of communication between science, politics and business. IZA is an independent, nonprofit limited liability company (Gesellschaft mit beschränkter Haftung) supported by the Deutsche Post AG. The center is associated with the University of Bonn and offers a stimulating research environment through its research networks, research support, and visitors and doctoral programs. IZA engages in (i) original and internationally competitive research in all fields of labor economics, (ii) development of policy concepts, and (iii) dissemination of research results and concepts to the interested public. The current research program deals with (1) mobility and flexibility of labor markets, (2) internationalization of labor markets and European integration, (3) the welfare state and labor markets, (4) labor markets in transition, (5) the future of work, (6) project evaluation and (7) general labor economics.

IZA Discussion Papers often represent preliminary work and are circulated to encourage discussion. Citation of such a paper should account for its provisional character. 


\begin{abstract}

\section{Counseling and Monitoring of Unemployed Workers: Theory and Evidence from a Controlled Social Experiment*}

We investigate the effect of counseling and monitoring on the individual transition rate to employment. We theoretically analyze these policies in a job search model with two search channels and endogenous search effort. In the empirical analysis we use unique administrative and survey data concerning a social experiment with full randomization and compliance. The results show that counseling and monitoring do not affect the exit rate to work. Monitoring causes a shift from informal to formal job search. We combine our empirical results to the results from our theoretical analysis and the existing empirical literature, to establish a comprehensive analysis of the effectiveness of these policies.
\end{abstract}

JEL Classification: J64, J65, J58

Keywords: Unemployment duration, search effort, active labor market policy, treatment, search channels, multi-tasking, randomized social experiment

Gerard J. van den Berg

Department of Economics

Free University Amsterdam

De Boelelaan 1105

1081 HV Amsterdam

The Netherlands

Tel.: +31204446132

Fax: +31204446020

Email: gjvdberg@xs4all.nl

\footnotetext{
${ }^{*}$ We are grateful to Regioplan and the Dutch National Institute for Social Security (LISV) for providing the data. We thank Ger Homburg and Lemina Hospers from Regioplan and Aart Kooreman from LISV for their information and very useful comments. We also thank Jaap Abbring, Pieter Gautier, Rafael Lalive, Richard Blundell, Cees Gorter, Rob Euwals, and participants at IZA and CEPR workshops in Berlin and Bonn, ESWM 2000, SOLE 2000, and seminars at IFAU-Uppsala, SOFI-Stockholm, Louvain-la-Neuve, and Amsterdam, for their comments.
} 


\section{Introduction}

There has recently been an increasing interest in stimulating re-employment of unemployed workers by so-called "active labor market policies". In this paper we evaluate the effects of two of such policies: counseling and monitoring. In The Netherlands, counseling and monitoring (C\&M) are provided by the local unemployment insurance (UI) agencies ${ }^{1}$ to UI recipients with relatively good labor market prospects. C\&M consists of monthly meetings with an employee of the local UI agency for a period of 6 months starting immediately after inflow into UI. During these meetings, recent job search activities are evaluated and a planning on the next period's job search activities is made. The main purpose of $\mathrm{C} \& \mathrm{M}$ is to reduce the duration of unemployment and consequently the total amount paid on UI benefits. These are therefore the outcome variables we focus on.

For a theoretical investigation of the effect of $C \& M$ on the exit rate to work we use a job search model with multiple search channels and endogenous search effort. This model is used to guide the interpretation of the empirical results. Many studies have demonstrated the importance of distinguishing between various search channels (see Blau and Robins, 1990, Fougère, Pradel and Roger, 1998, Holzer, 1988, Keeley and Robins, 1985, Koning, Van den Berg and Ridder, 1997, and Montgomery, 1991). We allow for formal and informal job search. Formal search means using formalized search methods like personnel advertisements and the public employment office. Informal search occurs when for example unemployed workers receive job offers through referral by an employed worker, a friend or a relative. C\&M only concerns formal job search, as it aims at increasing the efficiency of formal job search effort (or reducing the associated costs; this is the counseling component) and at closer monitoring of formal job search. Our theoretical model extends previously analyzed models, and our comparative statics results on the effects of active labor market policies generalize previously derived results. In addition, we establish a connection to the recent literature on principal-agent models with multi-tasking (see e.g. Holmström and Milgrom, 1991, Milgrom and Roberts, 1992, and Prendergast, 1999). In our context, the principal is the UI agency, the agents are the UI recipients, and the tasks are the search efforts along the formal and informal channel, where the former is much

\footnotetext{
${ }^{1}$ Although the main task of the local UI agencies concerns payment of UI benefits, the provision of training, schooling, etc. is also among their tasks. The public employment offices act as matching agents, not only to UI recipients, but also to welfare recipients and employed workers searching for (new) jobs.
} 
easier to monitor than the latter.

Our data are from a heavily controlled social experiment, with full randomization. Moreover, in the experiment, cross-over between treatment and control groups is impossible, at the moment of assignment or afterwards. The participants in the experiment are not informed in advance about the fact that the experiment is going on. None of the individuals in either group complained about their status. All this simplifies the econometric evaluation of average population treatment effects. It is not necessary to apply advanced econometric techniques to deal with sample selection bias from nonrandom participation and we do not have to rely on instrumental variables or functional form assumptions to identify the average treatment effect (see e.g. LaLonde, 1986).

Over the last years the use of randomized social experiments to evaluate active labor market policies has become somewhat more common. This has been particularly the case in the U.S. and Canada (see for example Ashenfelter, Ashmore and Deschênes, 1999, Card and Robins, 1998, Eberwein, Ham and LaLonde, 1997, and Meyer, 1995). In Europe this approach is very uncommon (in their comprehensive survey, Heckman, LaLonde and Smith, 1999, only list three European studies). Moreover, in many cases, the conceptual advantage of social experiments is reduced by practical problems of noncompliance.

The data and the experiment concern a sample of the inflow into unemployment in late 1998. In addition to the administrative database, we also have access to survey responses from the individuals. concerning aspects of their job search behavior and (activities by) the local UI agency. We match the two databases and we perform parametric and nonparametric analyses. The survey data provide insights into behavioral changes that could not have been obtained from administrative data only. In fact, these turn out to be pivotal in understanding social welfare effects of the policy.

The literature contains some studies on the effects of job search assistance and monitoring of unemployed workers, using data from randomized social experiments (see Ashenfelter, Ashmore and Deschênes, 1999, Gorter and Kalb, 1996, White and Lakey, 1992, Dolton and O'Neill, 1995, 1996, and the surveys in Björklund and Regnér, 1996, Fay, 1996, and Heckman, LaLonde and Smith, 1999). Together, these studies cover a range of programs, and the composition of the inflow as well as the macro-economic circumstances differ between them. We combine the empirical evidence from our administrative data and the survey data with the theoretical insights that we obtained and the results in this empirical literature, in order to enhance our understanding of the economic behavior of the unemployed individuals. This enables us to extrapolate our empirical results and 
to draw conclusions about a wider class of labor market policies that concern job search assistance and monitoring of search effort. As such, the present paper demonstrates that the return of a social experiment is not necessarily restricted to a single estimate of the average treatment effect (notwithstanding the general difficulties with comparisons between experiments concerning programs with self-selection; see Heckman, LaLonde and Smith, 1999).

The outline of this paper is as follows. In Section 2 we give a detailed description of the Dutch UI system and we discuss the C\&M treatment. Section 3 deals with the theoretical job search model that we use to interpret the results. In Sections 4 and 5 we discuss the setup of the experiment, the unique administrative database used to estimate the model and the follow-up survey. In Section 6 we present the estimation results and we perform some sensitivity analyses. We also discuss difficulties that may arise when one uses binary outcome methods to analyze duration data with treatments. In Section 7 we establish a comprehensive analysis of the effectiveness of the policies under consideration. Section 8 concludes the paper.

\section{Counseling and monitoring}

\subsection{Unemployment insurance}

In this section we describe the Dutch UI system in the late nineties. The aim of the Unemployment Law in The Netherlands is to insure employees against the financial consequences of unemployment. Excluded from this law are selfemployed and civil servants, who have an alternative arrangement. It insures around $70 \%$ of all workers. Here, we explain its essence, and we highlight aspects that are relevant for our purpose. Given that the observation window of our database covers less than 6 months after inflow, we mostly restrict attention to features that are important for that period.

If a worker younger than 65 years loses his job, he is entitled to UI benefits, provided that some conditions are fulfilled. The worker has to face a reduction in his original working hours of at least 5 hours per week, or half of his original working hours if less than 10 hours per week, he should not get paid for this working hour reduction and he should be willing to accept a new job. Furthermore, the individual should have had a job for at least 26 weeks in the past 39 weeks prior to the start of the unemployment period. The level of the benefits is fully determined by the history of labor force attachment. The income levels of other household members and private assets do not matter for UI. There are two 
possible schemes of UI benefits: $(i)$ wage-related benefits, and (ii) short-period benefits.

To be entitled to wage-related benefits, the unemployed worker must have worked at least 52 days during each of 4 years out of the past 5 calendar years. The wage-related benefits start with a period of initial benefits. The level of the initial benefits equals $70 \%$ of the wage in the job previous to unemployment with a maximum of 305.96 guilders per day (two Dutch guilders roughly equal one U.S. dollar). ${ }^{2}$ The exact duration of the entitlement period lies between 6 months and 5 years and depends on the employment history of the unemployed worker. For an entitlement period of 1 year, the unemployed worker must have had jobs for at least 10 years. For an entitlement period of 5 years, 40 years of working is required. After the entitlement to initial benefits expires, the unemployed worker receives extended benefits for a period of 2 years if his age was under 57.5 years at the first day of unemployment and 3.5 years otherwise. The extended benefits level is equal to $70 \%$ of the minimum wage or $70 \%$ of the wage in the last job before unemployment, whichever is lower.

Individuals who do not meet the requirement for collecting wage-related benefits, receive "short-period" benefits. The duration of receiving short-period benefits is always 6 months. The level of short-period benefits is similar to extended benefits, $70 \%$ of the minimum wage or $70 \%$ of the wage in the last job, whichever was lower.

If during the UI entitlement period the household income of a UI recipient decreases below "welfare level", the UI recipient may receive supplementary benefits to make up for the difference. ${ }^{3}$ This applies to both unemployed workers receiving wage-related benefits and short-period benefits. If, after the expiration of (either type of) UI benefits, the individual has not found a job, he may receive welfare benefits. These are means (household income) tested and related to what is considered to be the social minimum income.

According to the Unemployment Law, an unemployed worker has the following obligations in order to be entitled to UI benefits: $(i)$ prevent unnecessary job loss, (ii) take actions to prevent him from staying unemployed, so he has to search for a job and accept appropriate job offers, register as a job searcher at the public employment office, participate in education and training, etc., and (iii) keep the local UI agency informed about everything that is relevant to the payment of the UI benefits. If an unemployed worker does not comply to these rules, the

\footnotetext{
${ }^{2}$ Actually, less than $5 \%$ of the inflow in our data set receives the maximum benefits.

${ }^{3}$ At the end of 1997 only $7.2 \%$ of the stock of UI recipients collected supplementary benefits (LISV, 1998).
} 
local UI agency is authorized (not obliged) to apply a sanction to that worker. See Abbring, Van den Berg and Van Ours (1997) for a study on the effects of imposing sanctions on the exit rate to work. The administration of the UI system is organized at the level of the industry. There are 4 nation-wide UI agencies that each represent a number of sectors of the economy. In The Netherlands, at the end of 1997, 335.000 individuals collected UI benefits. ${ }^{4}$

At the intake meeting of UI, an individual is classified ("profiled") into one of four "types", based on individual characteristics such as work experience, age and education, and on some subjective measures such as expected job search behavior, flexibility, language skills and presentation skills. See Appendix 1 for a detailed description of the process of profiling. The Type I individuals are expected to have sufficient skills to find a job. The Type II and III individuals are considered not to have the skills to find work without assistance such as training and schooling. The Type IV individuals are the most disadvantaged and need more care. They are often unable to work or not obliged to search for work (lone parents with dependent children, drug addicts, etc.). In the inflow of unemployed workers into UI, $75 \%$ to $80 \%$ is classified as Type I, whereas in the stock of UI recipients, about $60 \%$ is classified as Type I. Newly unemployed who do not qualify for UI are also assigned to one of these four types, but among them the Type I fraction is lower.

All UI recipients have to send in weekly reports concerning job search activities. This can be done by mail. Once every four weeks, the UI agency determines whether the individual is still eligible for UI benefits.

\subsection{The treatment}

Since April 1998 all local UI agencies are obliged to support Type I unemployed workers by providing $\mathrm{C} \& \mathrm{M}$. Before that, $\mathrm{C} \& \mathrm{M}$ was provided by a fraction of agencies. During this pre-1998 period C\&M has been reformed a number of times, and the target population has changed along as well. For example, in the beginning almost all UI recipients were eligible for C\&M, but in periods in which the number of unemployed workers applying for UI benefits was high, only a limited number of them received $\mathrm{C} \& \mathrm{M}$. In its current form $\mathrm{C} \& \mathrm{M}$ is standardized, and all UI recipients eligible for C\&M actually receive it. Excluded are individuals who know at the date of UI registration that they will start a new job within 3 weeks and

\footnotetext{
${ }^{4}$ The Netherlands has 16 million inhabitants, of which 10.5 million are aged between 15 and 65. The 1997 labor force consists of 6.8 million individuals, of which 438.000 do not work. The 1997 yearly in- and outflow into and out of UI equal 486.000 and 531.700 individuals, respectively.
} 
Type I unemployed workers collecting short-period benefits. C\&M is a process of half a year. During this period the unemployed workers have a meeting at the local UI agency every 4 weeks.

The intake meeting of the C\&M takes place within three days after the start of the payment of the UI benefits. It takes about 45 minutes. The quality of application letters and the curriculum vitae are examined, the different channels through which work can be found are discussed and a planning is made about what the individual should do until the next meeting. Although the local UI agency can inform the unemployed worker about possible job entries, it is not allowed to act as an intermediate between unemployed workers and firms. Offering or pointing out specific vacancies to unemployed workers is the task of the public employment offices. Another important element of C\&M is to stimulate the unemployed worker to frequently contact the public employment offices. During this intake meeting it is stressed that a positive and active attitude toward job search is expected.

The follow up meetings take around 20 minutes and focus on applications to specific job vacancies and employers. During this meeting the planning of the previous meeting is evaluated and a planning for the next period is made. If the unemployed worker did not comply to the planning, he may be punished with a sanction in the form of a reduction of the UI benefits. The average sanction for insufficient job search is a $10 \%$ reduction of the UI benefits for a period of 2 months. However, both the magnitude and the duration of a benefit reduction may vary depending on the precise reason for why the sanction has been imposed (see Abbring, Van den Berg and Van Ours, 1997). Note that the C\&M requirements come on top of the reports on search activities that have to be sent in every week.

Provision of C\&M is cheap. The Dutch National Institute for Social Security pays the local UI agencies on average 335.98 guilders for providing C\&M. This is paid at the beginning of UI entitlement period and does not depend on the realized unemployment duration. Each C\&M meeting includes a check on whether the unemployed worker is still eligible for UI benefits. Performing this check would otherwise cost on average 38.61 guilders. So the Dutch National Institute for Social Security saves 38.61 guilders for each additional month that an individual collects UI benefits. For a number of reasons, the amounts may vary between individuals and local UI agencies. The figures mentioned above are average realized amounts. 


\section{Theoretical analysis}

\subsection{Job search with endogenous search effort and multiple search channels}

In this section we analyze the effects of $\mathrm{C} \& \mathrm{M}$ in a theoretical model of job search and unemployment duration. We start with a presentation of the basic model. In Subsections 3.2 and 3.3 we focus on the effects of counseling and monitoring, respectively. The model is based on the standard job search model with an endogenous search intensity (see e.g. Mortensen, 1986). We generalize the model by allowing job offers to arrive through formal as well as informal search channels, each with its own associated structural parameters and endogenous search intensity. Such a model has not been analyzed before in the literature.

Consider an unemployed worker searching for a job. This individual can search along the formal and the informal channel, which are denoted by subscripts 1 and 2, respectively. An amount of search effort $s_{i} \geq 0$ is devoted to search along channel $i$. This variable $s_{i}$, which is also called the search intensity for channel $i$, is to be chosen optimally by the unemployed worker. Job offers along search channel $i$ arrive at the individual according to a Poisson process with rate $\lambda_{i} s_{i}$.

A job offer along channel $i$ is characterized by a random drawing from a channel-specific wage offer distribution $F_{i}$. Arrival times and wage offers are independent across channels, and given the channel they are independent across time. For ease of exposition, we assume that $F_{1}$ and $F_{2}$ are continuous with a connected support stretching to infinity, on which the densities are positive. If a job offer arrives, the individual has to decide immediately whether to accept it or to reject it and continue searching. We do not allow for the possibility to reconsider job offers at a later stage. Furthermore, for ease of exposition, we assume that once a job is accepted, it will be kept forever, at the same wage. We thus exclude on-the-job-search and job loss. However, our results are robust with respect to this.

The costs of search are expressed by the function $c\left(s_{1}, s_{2}\right)$. We require $c$ to be increasing and convex in its arguments, with $c(0,0)=0$. Moreover, we require $\partial^{2} c /\left(\partial s_{1} \partial s_{2}\right)>0$ for $s_{1}, s_{2}>0$, to capture that the efforts along the two channels are relatively similar activities compared to most other ways to spend time and money, and to capture that a certain fraction of vacancies may be found along either channel. For these reasons, a specification for $c$ that is additive in $s_{1}$ and $s_{2}$ seems less plausible. In the literature on search models with endogenous search effort $s$ and a single search channel, the arrival rate and the search costs are 
generally taken to be proportional to $s$ and $s^{2}$, respectively (see the survey by Mortensen and Pissarides, 1999). We require that our specification for $c$ reduces to such a quadratic specification in case only one channel is used, or in case both channels are equivalent. So, our function $c$ has to be such that $c(s, 0), c(0, s)$ and $c(s, s)$ are quadratic in $s$. Finally, we require $c$ to lead to interior solutions for the optimal $s_{1}$ and $s_{2}$, because most individuals in the data report the use of both channels to search.

We take the following specification,

$$
c\left(s_{1}, s_{2}\right)=a_{0}\left(a_{1} s_{1}^{\gamma}+a_{2} s_{2}^{\gamma}\right)^{2 / \gamma}
$$

It is readily verified that this satisfies the above requirements if $a_{i}>0$ and $1<$ $\gamma<2$. It should be emphasized that most of our results carry over to alternative specifications for $c$ that satisfy some or all of the above requirements, for example a specification where $c$ is proportional to $\left(s_{1}+s_{2}\right)^{2}$, possibly with an additional fixed costless amount of effort, ${ }^{5}$ or a specification where $c$ is proportional to $\left(s_{1}^{2}+s_{2}^{2}\right)^{2}$. One additional reason for adopting (1) is that it leads to relatively transparent expressions.

For expositional convenience, we present results for the case where $\gamma=3 / 2$. Also, we normalize $a_{1}$ and $a_{2}$. As will become clear below, these are unidentified from $\lambda_{1}$ and $\lambda_{2}$, respectively. We specify

$$
c\left(s_{1}, s_{2}\right)=\frac{3}{4} c_{0}\left(\frac{2}{3} s_{1}^{\frac{3}{2}}+\frac{2}{3} s_{2}^{\frac{3}{2}}\right)^{4 / 3}
$$

with the parameter $c_{0}$ satisfying $0<c_{0}<\infty$.

During unemployment, benefits $b$ are received. Individuals maximize their expected discounted income over an infinite time horizon. The expected discounted income (or "value of search") and the discount rate are denoted by $R$ and $\rho$, respectively.

We make the following assumptions on the structural determinants. First,

$$
0<\lambda_{1}, \lambda_{2}, \mathrm{E}_{1}(w), \mathrm{E}_{2}(w), c_{0}, b, \rho<\infty
$$

where $\mathrm{E}_{i}(w)$ denotes the expected wage associated with job offer through search channel $i$. Also note that we do not require that $b \geq c\left(s_{1}, s_{2}\right)$. Secondly, all structural determinants are assumed to be constant over time. This assumption is made

\footnotetext{
${ }^{5}$ Fougère, Pradel and Roger (1998) and Sabatier (2001) effectively specify the arrival rate and the search costs as $\lambda s$ and $c_{0}(s-\underline{s})^{2}$, respectively, where $\lambda \underline{s}$ and $\lambda(s-\underline{s})$ are interpreted as the arrival rates along the formal and informal channel, respectively (or as the arrival rates of offers generated by the agency and offers generated by the worker).
} 
for expositional convenience. We know from Subsection 2.1 that this assumption is incorrect for $b$. After expiration of the entitlement to "initial benefits", $b$ drops to the level of the "extended benefits", and at a later stage it may drop to the welfare level. However, the expected unemployment duration of an unemployed worker who is eligible for C\&M is typically much shorter than the duration of entitlement to initial UI benefits. Van den Berg (1990) shows that if the exit rate to work is high and the moment at which $b$ decreases is not very close, then the anticipation of the future decrease of $b$ is very low, so, by approximation, the individual behaves as if $b$ is constant.

It is straightforward to derive from Bellman's equation that $R$ is the unique solution to

$$
\rho R=\max _{s_{1}, s_{2} \geq 0} b-\frac{3}{4} c_{0}\left(\frac{2}{3} s_{1}^{\frac{3}{2}}+\frac{2}{3} s_{2}^{\frac{3}{2}}\right)^{4 / 3}+\sum_{i=1}^{2} \lambda_{i} s_{i} \mathrm{E}_{i} \max \left\{\frac{w}{\rho}-R, 0\right\}
$$

(see Mortensen, 1986, and Albrecht, Holmlund and Lang, 1991), where the optimal search intensities are given by the values of $s_{1}$ and $s_{2}$ that maximize the right-hand side, and where the optimal job acceptance strategy is to accept if and only if the wage $w$ exceeds $\rho R$. This defines the unique reservation wage $\phi$ as $\phi=\rho R$. The optimal strategy of an unemployed worker can therefore be summarized by $\phi$ and the optimal search efforts $s_{1}$ and $s_{2}$. To proceed, it is useful to define

$$
\bar{F}_{i}(w)=1-F_{i}(w), \quad Q_{i}(x)=\int_{x}^{\infty} \bar{F}_{i}(w) d w
$$

These are the survivor function and the surplus function associated with $F_{i}$. By partial integration,

$$
\frac{Q_{i}(x)}{\bar{F}_{i}(x)}=\mathrm{E}_{i}(w-x \mid w>x)
$$

which is positive and finite for every $x$. This equation can be used to rewrite (3),

$$
\phi=\max _{s_{1}, s_{2} \geq 0} b-\frac{3}{4} c_{0}\left(\frac{2}{3} s_{1}^{\frac{3}{2}}+\frac{2}{3} s_{2}^{\frac{3}{2}}\right)^{4 / 3}+\sum_{i=1}^{2} \frac{\lambda_{i} s_{i}}{\rho} Q_{i}(\phi)
$$

The optimal search efforts given $\phi$ follow from maximization of the right-hand side of (4). The first order conditions state that

$$
\left(s_{1}^{3 / 2}+s_{2}^{3 / 2}\right)^{1 / 3} \cdot \sqrt{s_{i}}=\frac{(3 / 2)^{1 / 3} \lambda_{i}}{\rho c_{0}} Q_{i}(\phi)
$$


Because all components on the right-hand side are positive and finite for $i=$ 1,2 , the individual devotes a positive and finite amount of effort to each search channel. Note that the equation states that marginal search costs equal marginal benefits of search along channel $i$. By dividing both sides of (5) for $i=1$ by both sides for $i=2$, it follows that $\sqrt{s_{1} / s_{2}}=\lambda_{1} Q_{1}(\phi) /\left(\lambda_{2} Q_{2}(\phi)\right)$. This can be substituted into (5) to obtain explicit expressions for $s_{i}$ in terms of $\phi$ and the model determinants,

$$
s_{i}=\left(\frac{3}{2}\right)^{1 / 3} \cdot \frac{1}{c_{0} \rho} \cdot \frac{\lambda_{i}^{2}\left(Q_{i}(\phi)\right)^{2}}{\left[\lambda_{1}^{3}\left(Q_{1}(\phi)\right)^{3}+\lambda_{2}^{3}\left(Q_{2}(\phi)\right)^{3}\right]^{1 / 3}}
$$

If we substitute these into (4), we obtain an implicit expression for the optimal reservation wage in terms of the model determinants,

$$
\phi=b+\left(\frac{3}{16}\right)^{1 / 3} \frac{1}{c_{0} \rho^{2}}\left(\lambda_{1}^{3}\left(Q_{1}(\phi)\right)^{3}+\lambda_{2}^{3}\left(Q_{2}(\phi)\right)^{3}\right)^{2 / 3}
$$

By substituting the solution of this into (6), we obtain an expression for $s_{i}$ in terms of the structural determinants. This completes a recursive system of equations for the optimal strategy. Note from the above expression for $\phi$ that $0<b<\phi<\infty$.

The rate $\theta_{i}$ at which individuals find a job through a given search channel $i$ equals the product of the rate at which job offers arrive through this channel and the acceptance probability of such job offers, so $\theta_{i}=\lambda_{i} s_{i} \bar{F}_{i}(\phi)$. The transition rate from unemployment to employment $\theta$ equals the sum of these rates over both channels. By substituting (6) we obtain,

$$
\theta=\frac{(3 / 2)^{1 / 3}}{c_{0} \rho} \frac{\lambda_{1}^{3}\left(Q_{1}(\phi)\right)^{2} \bar{F}_{i}(\phi)+\lambda_{2}^{3}\left(Q_{2}(\phi)\right)^{2} \bar{F}_{i}(\phi)}{\left[\lambda_{1}^{3}\left(Q_{1}(\phi)\right)^{3}+\lambda_{2}^{3}\left(Q_{2}(\phi)\right)^{3}\right]^{1 / 3}}
$$

Note that due to the stationarity, this transition rate does not depend on elapsed unemployment duration or any other measure of time. In the remainder of this section we investigate how C\&M might affect it.

The optimal reservation wage and the channel-specific and total transition rates from unemployment to employment depend on $\lambda_{i}$ and $c_{0}$ solely by way of $\lambda_{i}^{2} / c_{0}$. This implies that with data on reservation wages, unemployment durations, and post-unemployment wages, it is in general not possible to identify $\lambda_{1}, \lambda_{2}$ and $c_{0}$. Moreover, the comparative statics effects of an increase in the efficiency $\lambda_{i}$ of a search channel, on $\phi, \theta_{i}$ and $\theta$, are qualitatively equivalent to the comparative statics effects of a decrease in the unit search cost. 


\subsection{The theoretical effect of counseling}

We assume that counseling is intended to facilitate search along the formal channel. There are a number of reasons why the efficiency of search along the formal channel may increase as a result of counseling. For example, the case worker at the local UI agency may help to improve the application letters and the curriculum vitae, employers provide information to the case worker about vacancies to which the unemployed worker can apply, the case worker makes appointments for the unemployed worker at the public employment office, etc. In general, search along the formal channel can be facilitated by way of an increase of $\lambda_{1}$ or a decrease of $c_{0}$. We are interested in the effect of this on $\theta$. For ease of exposition, and without loss of generality, we focus on the effect of $\lambda_{1}$ on $\theta$ assuming that $c_{0}$ is constant.

There is a substantial theoretical literature on the comparative statics effect of a job offer arrival rate on the exit rate out of unemployment. This literature assumes constant search intensities and is concerned with a single search channel. In that case, the job offer arrival rate has two opposite effects on the exit rate out of unemployment (and hence on the expected duration of unemployment). First, there is a positive effect on the exit rate because of the increased rate at which offers arrive. Secondly, there is a negative effect because of the increased selectivity of the searcher in face of this increased opportunity to leave unemployment (the reservation wage increases, and as a result the acceptance probability decreases). The sign and magnitude of the net effect depend on other variables affecting the optimal strategy of an unemployed individual (like the wage offer distribution and the subjective rate of discount) and therefore the sign of the net effect is ambiguous. The most general comparative statics results are in Van den Berg (1994), who shows that the effect is positive under very weak restrictions on the shape of the wage offer distribution. In this subsection, we extend these results to a setting with endogenous search intensities and multiple search channels.

In the model with endogenous search intensities and a single search channel, the parameter $\lambda$ also affects the optimal search intensity. This may give an additional boost to the actual rate at which offers arrive. At first sight this may suggest that in such a model the effect of $\lambda$ on $\theta$ is positive under weaker conditions than in the model with fixed search effort. However, the fact that the search intensity increases also implies that the worker can be even more selective with respect to the offers that arrive. In case of two search channels, the parameter $\lambda_{1}$ affects both search intensities and both channel-specific acceptance probabilities, thus complicating matters even further.

In the remainder we assume that the optimal $\phi$ lies within the support of both 
wage offer distributions $F_{i}(\cdot)$, so that $0<\bar{F}_{i}(\phi)<1$, thereby excluding trivial comparative statics cases.

Consider a wage offer distribution $F$, and define the associated function $\psi$ as follows:

$$
\psi(w)=\frac{f(w)}{1-F(w)}
$$

for all $w$ in the support of $F$. This is of course the hazard rate associated with the distribution $F$. For small $d w$ the expression $\psi(w) d w$ can be interpreted as the probability that a wage offer is in the interval $[w, w+d w)$ if it is given that this wage offer exceeds $w$. In order to avoid confusion with the hazard rate associated with the unemployment duration distribution, we will call $\psi$ the failure rate of $F$. Concerning the shape of $\psi$, all the insights from the literature on hazard rates of duration distributions carries through. For example, if $F$ has a fat right tail then $\psi(w)$ decreases for large $w$. See Van den Berg (1994) for a detailed discussion.

Now consider the following restriction on a wage offer distribution $F$,

Condition A The expression $w \psi(w)$ is non-decreasing in $w$, for every $w$ in the support of $F$.

Van den Berg (1994) shows that this is a weak restriction on probability distributions for non-negative random variables, in particular for random variables that are related to income variables. For example, it is satisfied by all distributions in the exponential, beta, Weibull, gamma, log-normal, Pareto, Generalized Beta-2, Singh-Maddala, F, and log-uniform families, the families of logistic, normal, t, and extreme value distributions that are truncated from below at or above zero, and the family of uniform distributions for which the lower point of support is non-negative. As a result, all families of distributions generally used to model wage offer distributions in job search models and other income-related distributions satisfy Condition A. ${ }^{6}$ We now proceed to present results for our model.

Proposition 1 If $F_{1}=F_{2}$ and if $F_{1}$ satisfies Condition $A$, then $d \theta / d \lambda_{1}>0$. In addition, $d \phi / d \lambda_{1}>0, d s_{1} / d \lambda_{1}>0, d s_{2} / d \lambda_{1}<0, d \theta_{1} / d \lambda_{1}>0$ and $d \theta_{2} / d \lambda_{1}<0$.

Proof. See Appendix 2. We should note that $F_{1}=F_{2}$ and Condition A are by no means necessary to obtain $d \theta / d \lambda_{1}>0$.

\footnotetext{
${ }^{6}$ Van den Berg (1994) shows that the effect of the job offer arrival rate on the exit rate out of unemployment is positive in his model if the wage offer distribution satisfies Condition A.
} 
If formal job search effort becomes more efficient, the optimal reservation wage increases. A higher value of $\lambda_{1}$ improves the present value of the unemployed worker and therefore he becomes more selective concerning the wages offered. If formal job search becomes more efficient, individuals also substitute informal job search effort into formal job search effort. It turns out that, under the conditions of Proposition 1, the rate at which the individual leaves unemployment by way of the formal (informal) channel increases (decreases), and that the first effect dominates in the total exit rate out of unemployment.

One may wonder whether $F_{1}=F_{2}$ is a reasonable assumption. We examine this from an empirical and a theoretical perspective. First, let us examine the empirical evidence. Koning, Van den Berg and Ridder (1997) use labor force survey data from The Netherlands to test whether the wage offer distributions are different between the formal and informal search channel. They do not reject the null hypothesis of equality. Lindeboom, Van Ours and Renes (1994) find that, in the Netherlands, informal wage offers have a relatively large acceptance probability, which suggests that the left tail of $F_{2}$ is thinner than of $F_{1}$, or that wages found along the informal channel are on average higher than those found along the formal channel. This difference in acceptance probability is also found for the U.S. by Holzer (1988).

The theoretical literature suggests that there may be reasons to suspect that $F_{2}$ first-order stochastically dominates $F_{1}$, that is, wages found along the informal channel are on average higher than those found along the formal channel. Mortensen and Vishwanath (1994) develop an equilibrium search model with a formal and an informal search channel and fixed search intensities. In this model, employed workers also search on the job for jobs with higher wages, so that in equilibrium firms paying high wages also have a relatively large workforce. If a worker finds a job by way of referral by currently employed workers, then the probability of getting an offer of a particular firm is proportional to the size of that firm. If a worker finds a job by way of formal applications to vacancies then the sampling of firms is uniform. Hence, informal search generates on average higher wage offers in equilibrium.

Now let us examine to what extent the results in Proposition 1 are actually sensitive to the assumption that $F_{1}=F_{2}$. If $F_{1}$ and $F_{2}$ are different then it is more difficult to provide elegant conditions under which $d \theta / d \lambda_{1}$ is positive. Intuitively it is clear that if $F_{2}$ has a very large amount of probability mass around to $\phi$ whereas $F_{1}$ does not, so that the corresponding densities at $\phi$ satisfy $f_{2}(\phi)>>f_{1}(\phi)$, then the effect may be negative. In such a case, the increase in $\lambda_{1}$ increases the present value and therefore the reservation wage $\phi$, but as a result a large number of 
informal job offers become unacceptable, and the exit rate out of unemployment may decrease. Simulations suggest that this scenario is particularly likely if most probability mass of $F_{1}$ is below $\phi$. But such a scenario is not in agreement to the empirical and theoretical evidence, which suggest that $F_{1}=F_{2}$ or $F_{2}$ dominates $F_{1}$. We therefore conclude that any differences in practice between $F_{1}$ and $F_{2}$ are not expected to result in a negative sign of $d \theta / d \lambda_{1}$.

The results of this subsection are robust with respect to the functional form of the search cost function and the way effort is modeled. In particular, they also follow in case of other cost functions with a positive cross-derivative with respect to $s_{1}, s_{2}$, possibly with an additional fixed costless amount of effort, and even in case of cost functions that are additive in terms that depend on $s_{1}$ and $s_{2}$, respectively.

\subsection{The theoretical effect of monitoring}

We assume that the monitoring in C\&M concerns the formal job search effort $s_{1}$ but not the informal search effort. The local UI agency can check the number of times the UI recipient responds on a job advertisement, the number of application letters written, subscription at public employment offices, etc. It is for the local UI agency much more difficult to measure how often an individual asks friends and relatives about job openings. When providing C\&M the monitoring effort of the local UI agency therefore focuses on search along the formal channel. Specifically, the agency imposes a minimum search effort (or threshold value) devoted to formal job search denoted by $s_{1}^{*}$.

Full compliance can be achieved by perfect monitoring of formal job search effort or by a sufficiently severe punishment of noncompliance. In practice, the most common punishment in case of noncompliance is a sanction, which is a temporary benefit reduction (see Abbring, Van den Berg and Van Ours, 1997). In the subsequent sections of this paper we show that monitoring is actually regarded to be quite intensive, and that sanctions are virtually absent among the individuals who receive $\mathrm{C} \& \mathrm{M}$. We therefore simply assume that there is no noncompliance.

It is clear that if the optimal formal job search effort $s_{1}$ in the unrestricted case lies above this threshold value, then the individual will not change his behavior, so monitoring does not have any effect. We focus on the more interesting case in which the required effort is higher than the effort in the absence of monitoring. In this case, the optimal strategy can be summarized merely by $\phi$ and $s_{2}$. To see what can happen when monitoring is introduced, it is instructive to examine a 
slightly more special model specification, with the "perfect substitution" search cost function

$$
c\left(s_{1}, s_{2}\right)=\frac{1}{2} c_{0}\left(s_{1}+s_{2}\right)^{2}
$$

with $0<c_{0}<\infty$. In addition, we take $\lambda_{1}=\lambda_{2}(=: \lambda)$ and $F_{1}=F_{2}(=: F)$, In this case,

$$
\rho R=\max _{s_{1}, s_{2} \geq 0} b-\frac{1}{2} c_{0}\left(s_{1}+s_{2}\right)^{2}+\lambda\left(s_{1}+s_{2}\right) \operatorname{Emax}\left\{\frac{w}{\rho}-R, 0\right\}
$$

replaces equation (3), with again $\phi=\rho R$. It follows that the optimum search intensities satisfy

$$
s_{1}+s_{2}=\frac{\lambda}{\rho c_{0}} Q(\phi)
$$

but the optimum values of the separate search intensities $s_{i}$ are undetermined. Any combination of $s_{1} \geq 0$ and $s_{2} \geq 0$ such that $s_{1}+s_{2}$ satisfies (11) is optimal.

Suppose that the individual levels of $s_{1}$ and $s_{2}$ are determined outside the model, and suppose that the agency imposes $s_{1}^{*}$, with $s_{1}^{*}$ exceeding the level of $s_{1}$ in the unrestricted case but falling short of the level of $s_{1}+s_{2}$ in the unrestricted case. Then search effort along the formal channel increases to $s_{1}^{*}$, but this is fully compensated by a decrease in the optimal effort $s_{2}$ along the informal channel, such that $s_{1}+s_{2}$ remains constant. This results in the same value of $s_{1}+s_{2}$ as in the unrestricted case. As a result, nothing happens to $\phi$ and $\theta$. Increased monitoring is ineffective due to effort substitution. Keeley and Robins (1985) also mention substitution of search effort in response to monitoring of the formal search channel. However, they do not provide a formal theoretical analysis.

Now let us return to the more general model specification that we used throughout this section. The optimal reservation wage $\phi$ follows from equation (4), where the right-hand side is now maximized over $s_{2}$ while $s_{1}$ is fixed at $s_{1}^{*}$. Note that the marginal returns to formal job search effort are now lower than the marginal costs. The optimal reservation wage is decreasing in the binding minimum required formal search effort level. Unemployed workers are forced to behave sub-optimally, so being unemployed becomes less attractive, and therefore they are willing to accept jobs with lower wages. For essentially the same reason, unemployed workers would not participate voluntarily in a monitoring scheme with a binding minimum search effort. ${ }^{7}$ Of course, the advantages of monitoring

\footnotetext{
${ }^{7}$ They may participate voluntarily in a counseling scheme that increases $\lambda_{1}$, because this increases the expected present value of being unemployed. A combination of the two schemes may be attractive to the unemployed workers, depending on the parameter values.
} 
are outside of the individual's decision problem. The agency may want to reduce the total payment of UI (i.e., to increase $\theta$ by way of monitoring) because it believes that the advantages of this outweigh the reduction of the unemployed worker's present value.

The optimal $s_{2}$ given $\phi$ satisfies equation (5) for $i=2$, with again $s_{1}$ fixed at $s_{1}^{*}$. From this equation it can be seen that an increase in $s_{1}^{*}$ has two effects on $s_{2}$. First, the marginal costs of using the informal channel increase, at any level of $s_{2}$. This has a negative effect on the optimal $s_{2}$. Secondly, the marginal returns of using the informal channel increase, because unemployment becomes less attractive ( $\phi$ decreases, so $Q_{2}(\phi)$ increases). This has a positive effect on the optimal $s_{2}$. These two effects could be labeled the substitution and income effect, respectively. It seems difficult to derive simple conditions under which the substitution effect always dominates (i.e., $d s_{2} / d s_{1}^{*}<0$ ), but it is very easy to construct wide ranges of examples where this holds, and indeed this seems to be the regular case. If the individual is forced to increase his effort along the formal channel then the marginal costs of using the informal channel increase, and he will reduce his effort along the informal channel.

Concerning the over-all effect of $s_{1}^{*}$ on $\theta$, again it seems difficult to derive simple conditions under which this is always positive or negative. However, it is not difficult to construct numerical examples where the effect is actually negative (especially when $\lambda_{1}<\lambda_{2}$ ). In those cases, the effect of the imposed increase in effort along the formal channel is more than offset by the implied decrease in effort along the informal channel. Monitoring then has the perverse effect of reducing the transition rate to employment. ${ }^{8}$ In the literature, this effect has not been discussed before. Note that it implies that in this case monitoring is an ineffective policy.

In some specific cases, monitoring may increase $\theta$. Notably, if $s_{2}$ is already very small then there is not much scope for substitution in response to imposition of $s_{1}^{*}$, as $s_{2}$ is bounded from below by zero. Also, if $\lambda_{2}$ is very small (which may in turn cause $s_{2}$ to be small) then the reduction of $s_{2}$ may have a smaller effect on $\theta$ than the increase of $s_{1}$. In the limiting case of $\lambda_{2}=0$, we are in a model with a single channel, and a binding $s_{1}^{*}$ always increases $\theta$ (Abbring, Van den Berg and Van Ours, 1997). The empirical literature is informative on the use

\footnotetext{
${ }^{8}$ Again, these results can be generalized to model specifications with other cost functions. However, in the unrealistic case where total search costs are additive in the search costs per channel, it can be shown that the imposition of a binding minimum required search effort along the formal channel has a positive effect on $\theta$. In that case, the imposition of $s_{1}^{*}$ entails an income effect on $s_{2}$ but not a substitution effect.
} 
of different search channels by different types of workers. There is overwhelming evidence that workers with characteristics such that their chances to find a job are low, long-term unemployed workers, workers in a labor market with unfavorable circumstances, and workers in recessions, all rely to a relatively large extent on formal search (see the references earlier in this section and references therein). These individuals do not have access to informal search channels, or their informal search channel has dried up. For such individuals, monitoring may have a positive effect on $\theta$.

As we have seen, monitoring forces individuals to behave sub-optimally. Suppose for convenience that $F_{1}=F_{2}$. If $\lambda_{1}<\lambda_{2}$ then the sub-optimal behavior entails the use of the inefficient search channel at the expense of the efficient channel. Even if the over-all effect on $\theta$ is positive, it seems hard to imagine that external advantages of monitoring would warrant such a policy.

Some of our results on monitoring bear an analogy to results in the principalagent models with multi-tasking (for overviews of the theoretical results and empirical evidence, see Milgrom and Roberts, 1992, Prendergast, 1999, and Dewatripont, Jewitt and Tirole, 2000). Holmström and Milgrom (1991) study a setting where workers perform multiple tasks and efforts are substitutes in the agent's cost function. In case the employers are only capable of monitoring a single task, contracts based on performance of this single task are inefficient and give rise to dysfunctional behavioral responses. This induces the use of low-powered incentives. In our context, this may mean that the UI agency should pay UI benefits without requiring minimum search effort requirements, even when the UI agency has information on search effort along the formal channel.

\section{The experiment}

\subsection{Design and implementation}

The scale of the social experiment is modest. The experiment concerns all Type I unemployed workers, who started collecting UI benefits between August 24 and December 2, 1998 at two local branches of one particular nation-wide UI agency. The experiment ended on February 8, 1999. Only individuals who already know at the beginning of their UI entitlement period that they will start a new job within 3 weeks are excluded from the experiment, as they are not entitled to C\&M. The local agencies are in two of the largest cities of The Netherlands. In the remainder we simply refer to these cities as City 1 and City 2. The inflow into UI at these local agencies is relatively large, and the agencies have a good 
reputation for carrying out C\&M activities in a highly orderly fashion. Both facts have played a role in the selection of these local agencies as venues for the experiment.

In the initial setup of the experiment individuals were supposed to be randomly assigned to 5 groups. The first group would be the control group and the individuals in the other groups would all receive C\&M. After the experiment ended one of the 4 "treatment" groups would be chosen randomly to construct the final database together with the control group. This final database would thus approximately count the same number of individuals who received $\mathrm{C} \& \mathrm{M}$ as individuals who did not receive it. The main purpose of this setup was to avoid that the local UI agencies would give special attention to the individuals in the treatment group, which would bias the results of the experiment. As mentioned in Subsection 2.2 the local UI agencies get paid for providing C\&M and are therefore eager to get a positive evaluation of C\&M. However, because the inflow of Type I unemployed workers into UI was too small, the initial setup was not followed. In practice, about $50 \%$ of the inflow was assigned to the treatment group and the control group. All individuals were included in the final database.

During the UI intake meeting, the employee of the local UI agency establishes if the UI recipients is eligible for receiving C\&M. An independent agency then decides based on a series of random numbers, which were realized in SPSS before the start of the experiment, whether this unemployed worker is selected in the treatment group or the control group. At this stage the independent agency only knows the unique ID-number of the individual. Individuals selected in the treatment group have to show up at an intake meeting of C\&M within 3 days. The unemployed workers in the control group only communicate with the local UI agency by way of sending in written forms stating the current status of their job search activities.

At the local UI agency in City 2, the experiment was not performed exactly as prescribed. At the first intake meeting not all the eligibility criteria for receiving $\mathrm{C} \& \mathrm{M}$ were checked. In particular, some Type II unemployed workers entered the experiment. The Type II unemployed workers who were selected into the treatment group were identified as being a Type II unemployed worker at the intake meeting of C\&M and were excluded from the experiment. However, if such an individual was selected into the control group, it was not noted that the UI recipient should not have participated in the experiment. We therefore rechecked the individuals in the control group in City 2 on the criteria for being Type I. This resulted in exclusion of a part of the control group from the data. However, it cannot be completely ruled out that there are still a few Type II unemployed 
workers left in the control group. Because on average Type II unemployed workers have worse labor market skills and therefore have longer expected spells of unemployment (see Subsection 2.1), the estimated effect of C\&M on the exit rate to work might be slightly upwards biased.

\subsection{Issues concerning the treatment evaluation}

In some of our empirical analyses, we condition on individual characteristics. Also, in some of our analyses, we allow the treatment effect to be heterogeneous (see Section 6 below for more details). See Heckman, LaLonde and Smith (1999) for a survey of different summary measures of treatment effects. Note that we aim to compare two policy systems. In particular, we aim to estimate the average effect across the population of UI entrants. In general (i.e., outside of the experiment), exactly one of the two policy systems applies, in which case it applies to all members of the target population. "Program participation" is then compulsory. In our experiment, assignment is compulsory, so there is no noncompliance with the actual assignment. We therefore do not face the difficulties of inferring actual treatment effects from social experiments if actual participation (outside the experiment) is subject to (self-)selection or if noncompliance is possible in the experiment (see Heckman, LaLonde and Smith, 1999). We now address this in more detail by focusing on aspects that potentially complicate the use of social experiments to infer treatment effects.

First, the target population for $\mathrm{C} \& \mathrm{M}$ is defined as a subset of the inflow into UI, and individuals may let the decision to apply for UI depend on whether C\&M is provided. In the experiment, before the randomization occurs, all individuals may expect to be treated. But the composition of the inflow may differ between a world without C\&M and a world with C\&M. However, recall that the individuals in the target population have a relatively high UI benefits level, and compared to that, the (dis)utility of C\&M seems very small. It is therefore unlikely that the take-up rate depends on $\mathrm{C} \& \mathrm{M}$.

Secondly, individuals in the inflow into UI may subsequently try to select themselves into or out of the Type I category, depending on whether C\&M is present. But if an individual who would be assigned to Type I (i.e. to the target population) dislikes C\&M, then he probably dislikes the treatments for the other Types even more, as those are more intensive. Non-Type I individuals are unlikely to be able to influence their classification, but it is possible that case workers classify Type II individuals more easily as Type I if they feel that C\&M helps them more than the treatments intended for Type II individuals. In that case the 
population of Type I individuals in the world without C\&M has higher exit rates to work than the control group in the experiment, and we may over-estimate the positive effect of $\mathrm{C} \& \mathrm{M}$ on the individual exit rate.

Thirdly, individuals in the treatment group may withdraw from treatment. This could be done by demanding the same status as individuals in the control group, or simply by not showing up at the monthly C\&M meetings. The first type of withdrawal can only occur if the individual is aware of the experiment and his assigned status. Individuals were not informed about the fact that they participated in an experiment, and therefore neither about their status. Moreover, both types of withdrawal result in imposition of a punitive sanction. As shown in Section 5.1 below, the sanction rates among individuals in the treatment and control groups are very small and have the same order of magnitude. This means that withdrawal from the treatment group is absent or virtually absent.

. Fourthly, individuals in the control group may demand treatment. However, this did not occur in the present experiment, and in fact none of the individuals in the control group complained about not receiving C\&M. Of course, individuals in the control group may look for substitute job search assistance treatment from other sources, but this would also occur in a world without C\&M.

Fifthly, the local agencies involved in the experiment have a reputation for carrying out C\&M activities in a highly orderly fashion. This may mean that $\mathrm{C} \& \mathrm{M}$ at other agencies is less intense. For this reason we might over-estimate the nation-wide effect of C\&M.

Finally, it should be acknowledged that various indirect and equilibrium effects may bias the estimation of the over-all policy effect from a social experiment. In our case, individuals in the control group may suffer more than in a world without $\mathrm{C} \& \mathrm{M}$, and we over-estimate the positive effect of $\mathrm{C} \& \mathrm{M}$ on the exit rate to work. We conclude this section by noting that if the effect estimate is biased, then it is likely to over-estimate the positive effect on the exit rate to work.

\section{The data}

\subsection{Data description}

The database contains administrative information on 394 individuals who participated in the experiment, i.e. who started to collect UI benefits between August 24 and December 2, 1998 in City 1 and 2. All information on events is daily, 
i.e. we observe the exact day of inflow into and outflow out of UI. ${ }^{9}$ The latter is only observed if it occurs before the moment at which the experiment ends and the database is constructed (February 8, 1999). All spells which are not finished by this date $(42 \%)$ are right-censored. For the uncensored spells we observe the exit destination, which is employment in $87.5 \%$ of the cases. The most frequently observed other exit destination is illness (8.9\%); other possibilities are: leaving the city, prison, or not accepting suitable work. There is no systematic difference in how often these other exits occur in the treatment (receiving $C \& M$ ) and the control (not receiving $\mathrm{C} \& \mathrm{M}$ ) group. Because we have administrative data, the empirical analyses do not suffer from selective nonresponse or attrition from the database. However, we do not observe multiple unemployment spells per individual. There is no information about events or income levels after exit out of unemployment.

The inflow into UI is larger in City 2 than in City 1. The database includes 249 individuals living in City 2 and 155 individuals living in City 1. To get an indication of the local labor market conditions, we briefly discuss some socioeconomic characteristics of both cities. These are collected in 1997. In both cities slightly more than $60 \%$ of the population participates in the labor force and of the labor force around $10 \%$ is registered as being unemployed. The main difference between these cities is the percentage of immigrants. In City 1, 20\% of the population consists of immigrants or children of immigrants, while this is more than $40 \%$ in City 2. More individuals were selected into the treatment group than in the control group, 205 individuals received C\&M and 189 were excluded from C\&M.

In the empirical analyses we use the values of the explanatory variables $x$ at the moment of inflow. Because the administrative database only contains variables that are needed by the UI agency, the number of variables in the database is limited. For example we do not have any information on profession and the level of education. Except for the city of residence and receiving C\&M or not, we observe the standard personal characteristics, gender, age and household situation (being single or living together with a partner). In addition, we observe if the individual has ever received UI benefits before. Furthermore, we know the benefits level per day and the number of days per week the unemployed worker

\footnotetext{
${ }^{9}$ As mentioned in Subsection 2.1 UI recipients are not always full-time unemployed, i.e. they may have lost only part of their working hours and still work for the remaining hours. Therefore, the relevant events are the start of the period of collecting UI benefits and the end of this period. However, we simply refer to this period of collecting UI benefits as unemployment and to UI recipients as unemployed workers.
} 
is eligible for collecting UI benefits. This latter variable is the original weekly working hours reduction divided by 8 (the number of working hours per day). Finally, we observe if the local UI agency imposed a sanction on the UI recipient. We do not have any information on the reason why the sanction was imposed or the size and the duration of the benefit reduction. In the database, the percentage of individuals who got a sanction imposed was less than $3 \%$, among those who received $\mathrm{C} \& \mathrm{M}$ as well as among those who did not receive $\mathrm{C} \& \mathrm{M}$.

Table 1 provides some statistics of the data set. Of the UI recipients who received C\&M 52\% exit to work before February 8, 1999, while $47 \%$ of the control group found a job. Since some of the individuals were "exposed to the risk" of finding work since the end of August 1998, while others entered only in the beginning of December 1998, it is difficult to draw conclusions from this number. Nevertheless, we can get a first impression by comparing such probabilities for different groups. In most cases, individuals with a particular characteristic are more likely to find work if they receive C\&M. Furthermore, males, unemployed workers who collected UI benefits before and single living individuals have higher exit probabilities than their counterparts, although the differences are small. Individuals who exit to work are on average younger, receive higher benefits per day and receive these benefits for more days per week. But again the difference are small. There does not seem to be much difference in exit probabilities between individuals living in City 1 and in City 2.

To check the randomization of treatment assignment we estimate a probit model for being assigned to the treatment or to the control group. As exogenous variables we use the explanatory (individual) characteristics mentioned above. Table 2 provides the parameter estimates. Only the dummy variable indicating whether the individual is single has a significant effect on the probability of being in the treatment group. This reflects an unequal share of the unemployed individuals in the control group who are living in City 2 and are not single. In the previous section we mentioned that there might be some problems with the randomization at the local UI agency in City 2. However, there is no relation between the individual's household situation and being a Type I or a Type II unemployed worker (see Appendix 1).

\subsection{The data from the follow-up survey}

A survey questionnaire was sent by mail to all participants after the experiment was completed. Because the mailing date was before the final check on the administrative database, more individuals received the questionnaire than there are 
individuals in the latter database (see Section 4). In total 500 individuals received the questionnaire. The response rate was $33 \%$. From the 394 individuals in the administrative data, 167 responded (79 in the treatment group and 88 in the control group). We tried to match the survey respondents to the individuals in the administrative database. The main advantage of this is that it results in a larger number of explanatory variables for the analysis of the exit to work. To match records, we used information on the month of birth, the city of residence, gender, treatment status, having collected UI benefits before, current labor market status, and day of starting collecting UI benefits. However, due to a large amount of item nonresponse on these variables, we only succeeded in matching 49 individuals in the treatment group and 55 individuals in the control group.

The survey includes questions on how the unemployed workers evaluate C\&M and on which search channels they have used, in addition to subjective evaluations of satisfaction with aspects of the benefits and re-employment system. The survey does not include any questions about what occurred after leaving the UI benefits system, for example concerning accepted jobs. We focus on the results based on the full sample of all survey respondents. The sample that can be matched to the administrative data invariably gives the same conclusions. ${ }^{10}$

We start with an examination of how the respondents in the treatment group characterize C\&M. Table 3 provides the numbers of respondents who report that a given topic or activity had taken place during C\&M meetings. The most frequently reported topics and activities are "agreements on the number of job applications" and "providing information about my UI benefits". The other activities that are mentioned by at least half of the respondents are "discussing my labor market history and education" and "checking my job applications". All these activities are more controlling than advisory. "Suggestions concerning applications" is only mentioned by one third of the respondents. Clearly, monitoring is a more important component of $\mathrm{C} \& \mathrm{M}$ than counseling.

A particularly interesting survey variable concerns the use of job search channels. The individuals were asked to report from a list of possible job search channels which channels they had actually used during their spell of collecting UI benefits. Table 4 displays how often the different channels are used by the UI recipients in the control and the treatment group. The individuals in the treatment group make more use of all formal job search channels such as public employment

\footnotetext{
${ }^{10}$ The survey data also contain self-reported numbers of job applications. However, these data display an extremely large amount of dispersion. Estimates of count data models for these data are extremely sensitive with respect to the value at which high numbers are censored or truncated. Apparently there is a very large amount of measurement error in these data.
} 
offices, (commercial) employment agencies, the local UI agency and job advertisements in newspapers. Informal job search channels like open application letters and search through friends and relatives, are more often used by the unemployed workers who did not receive C\&M. In the treatment group around $95 \%$ of the individuals used at least one formal job search channel, while this is $85 \%$ in the control group. On the other hand, almost $80 \%$ of the UI recipients in the control group used at least one informal job search channel against around $55 \%$ in the treatment group. In Subsection 6.5 we provide a formal multivariate analysis of these variables.

\section{$6 \quad$ Estimation results}

\subsection{Nonparametric analysis of the duration until exit to work}

We estimate the effect on exit to work with nonparametric and parametric methods, with duration models and with limited-dependent variable models. Figure 1 presents the nonparametric (Kaplan-Meier) estimates of the survivor functions until exit to work, in the treatment and control group. Here, as well as below, exit to non-work destinations is treated as independent right-censoring of the duration until exit to work. There is hardly any difference between the two lines during the first 14 weeks of unemployment. After that, the survivor function decreases faster for the individuals in the treatment group, indicating that, in this period, UI recipients who receive $\mathrm{C} \& \mathrm{M}$ have higher re-employment probabilities. However, the estimates at high durations are only based on a few observations. The figure also plots the nonparametric confidence bands for the survivor function estimates. Clearly, the survivor function estimates are both within the bands corresponding to both functions. To investigate further whether the survivor functions differ across the groups, we perform the nonparametric log-rank test. The test statistic equals 0.62. Since this test statistic has a standard normal distribution, it implies that we can not reject the null hypothesis that the survivor functions are the same.

Figure 2 presents the nonparametric estimates of the hazard rates of the distribution of the duration until exit to work. Obviously, these are very similar as well. The estimate for the control group peaks at $t=2$ (i.e., after 3 weeks) whereas the estimate for the treatment group peaks at $t=3$ (i.e., after 4 weeks). This can be explained to some extent by the fact that the first $\mathrm{C} \& \mathrm{M}$ meeting of the individuals in the treatment group takes place a few days after registration. 
These individuals may postpone any search activity until after this meeting if they expect the case workers to provide valuable suggestions. In such a case the search intensity of the individuals in the treatment group may start off more slowly. However, note that the differences between the two estimated hazard rates may very well reflect sampling errors, as each curve is based on a sample of about 200 individuals.

\subsection{Estimation of duration models for exit to work}

Now let us turn to the estimation of duration models. These concern common reduced-form hazard rate models (see for example Lancaster, 1990). ${ }^{11}$ Consider individuals receiving UI benefits for $t$ units of time. We assume that differences in transition rates from unemployment to work can be characterized by observed individual characteristics $x$, an indicator function for being in the treatment group $z$, unobserved characteristics $v$, and the elapsed UI duration itself. We assume $v, x$ to be constant over time (the data do not allow us to observe changes in $x$ ) and $v$ to be independent of $x$. In a social experiment, $z$ is by definition independent of $v, x$.

The transition rate from UI to work at $t$ conditional on $x, z$ and $v$ is denoted by $\theta(t \mid x, z, v)$ and is assumed to have the familiar Mixed Proportional Hazard $(\mathrm{MPH})$ specification

$$
\theta(t \mid x, z, v)=\lambda(t) \exp \left(x^{\prime} \beta+z \delta+v\right)
$$

in which $\lambda(t)$ represents the individual duration dependence. The proportionate treatment effect $\exp (\delta)$ on the exit rate to work for an individual with characteristics $x, v$ at duration $t$ is homogeneous (we also estimate models where $\delta$ is allowed to depend on individual characteristics, and models with full interaction between the treatment effect and the other model determinants; see below).

Let $t$ be the realized duration when leaving to employment. The conditional density function of $t \mid x, z, v$ can be written as

$$
f(t \mid x, z, v)=\theta(t \mid x, z, v) \exp \left(-\int_{0}^{t} \theta(s \mid x, z, v) d s\right)
$$

Note that although the proportionate treatment effect on the individual exit rate is homogeneous, the proportionate treatment effect on the individual prob-

\footnotetext{
${ }^{11}$ Because we do not have any information on wages, reservation wages and job offers, we can not econometrically identify the job search model presented in Section 3. See Fougère, Pradel and Roger (1998) for a careful structural empirical analysis of a job search model that allows for different search channels.
} 
ability of exit within a certain time interval is not. The individual probability of exit to work within the interval $(0, t)$ equals

$$
1-\exp \left(-e^{x^{\prime} \beta+z \delta+v} \int_{0}^{t} \lambda(s) d s\right)
$$

and the ratio of this probability with $z=1$ and this probability with $z=0$ depends on $t, x$, and $v$.

The density function of $t$ conditional on $x$ and $z$ is derived by integration of the above density over $v$. From this, it is straightforward to derive the individual contributions to the likelihood function. The use of a flow sample of UI spells means that all spells are observed from the start, so that we do not have initial condition problems. The right-censoring in the data is exogenous and is therefore dealt with in a straightforward manner.

For the duration dependence function and the distribution function of the unobserved heterogeneity we take flexible specifications. Specifically, we take $\lambda(t)$ to have a piecewise constant specification,

$$
\lambda(t)=\exp \left(\sum_{j=1,2, \ldots} \lambda_{j} I_{j}(t)\right)
$$

where $j$ is a subscript for time intervals and $I_{j}(t)$ are time-varying dummy variables that are one in consecutive time intervals. Note that with an increasing number of time intervals any duration dependence pattern can be approximated arbitrarily closely. We take the distribution function of the unobserved heterogeneity to be discrete with unrestricted mass point locations.

The models are estimated with Maximum Likelihood. We take the unit of time to be one week. The piecewise constant duration dependence is specified in terms of 4 weeks and we normalize by taking $\lambda_{1}=0$. Initially, we allow the unobserved heterogeneity distribution to have two points of support. Hence, we estimate the parameters $\lambda_{t}(t=2, \ldots, 5), \delta, v_{1}, v_{2}, p_{1}$ and $\beta$, where $\beta$ is a vector of 8 parameters (not including an intercept). Table 5 presents the parameter estimates. We do not find any unobserved heterogeneity. During the optimization of the likelihood, the points of support converge to a single point. The computed standard errors of all other parameters are conditional on absence of unobserved heterogeneity.

The parameter of interest is $\delta$, which captures the treatment effect on the exit rate to work. The estimated value of $\delta$ is positive but is insignificantly different from 0. Providing C\&M to UI recipient raises the individual transition rate to employment only with approximately $6 \%(=\exp (0.063)-1)$, suggesting that in its current setup C\&M is not a very useful labor market policy for stimulating 
re-employment. The median of the duration distribution in the data reduces with about a week. ${ }^{12}$

The observation period is relatively short. Without any additional assumption, we can only estimate the duration dependence during the first 20 weeks. In this period the pattern of duration dependence is hump-shaped. After the first duration interval of 4 weeks, we observe a significant increase and from the second interval onwards we find that the hazard rate is slightly decreasing. The duration dependence significantly differs from being flat, $\lambda_{i}$ equals 0 for all $i=1, \ldots, 5$. The Likelihood Ratio test statistic on joint significance is equal to 11.4. Since the null hypothesis restricts 4 parameters $\left(\lambda_{2}, \ldots, \lambda_{5}\right)$, we reject it at the $5 \%$ significance level. Obviously, there are some factors like for example stigmatization and discouragement which affect the re-employment probabilities already in an early stage of unemployment.

Now let us turn to the covariate effects on the transition rate to employment. Only the level of the daily UI benefits has a significant effect on individual exit rates. UI recipients who receive daily benefits of around 162 guilders have the highest re-employment probabilities. This is approximately the median of the daily benefits level of the UI recipients in our dataset and it is just below the average benefits level. According to the job search models in Section 3, a higher benefits level increases the reservation wage, and the re-employment probabilities decrease. However, the benefits level at the early stage of UI depends mainly on the wage in the job previous to unemployment (see Subsection 2.1). Because the wage reflects the productivity of the worker, the benefits level most likely depends on the worker's productivity. Because high productivity workers are more attractive to employers, these workers have higher exit rates to work. Our database does not include any other variable which can be used as a measure of productivity. Therefore, the benefits level also picks up some of the effects of differences in productivity between workers, which may explain why we do not find that the exit rate to work is strictly decreasing in the benefits level.

None of the other covariates has any significant effect. According to a Likeli-

\footnotetext{
${ }^{12}$ Based on the estimated duration model, C\&M reduces the average (over $x$ ) expected duration with around 25 days, with an estimated standard error of 61 days, while the average (over $x$ ) median duration is reduced with about 15 days (standard error is 36 days). The estimated duration densities (and therefore the estimated means and medians) are obtained by extrapolation of the estimated hazard rate to durations exceeding the observation period. As a result, the shapes of the estimated piecewise constant duration dependence specifications at high durations strongly affect the estimated differences of the means and medians. Also, we implicitly assume that the effect of $\mathrm{C} \& \mathrm{M}$ is constant during the whole spell, even after 6 months when the treatment period expires.
} 
hood Ratio test they are also not jointly significant (the test statistic equals 9.2). We also estimated models that include in $x$ the squared values of log age and the number of days receiving UI benefits per week. Both these additional variables hardly affect the optimal value of the loglikelihood function. Although not having any significant impact on transition rates from unemployment to employment, we shortly discuss the covariate effects of the other explanatory variables. Gender and marital status seem to be the less important covariates in the transition rate to employment. The other covariates are quantitatively slightly more important. The re-employment probabilities for the unemployed workers living in City 2 are smaller than for unemployed workers in City 1, which reflects the differences in local labor market conditions between these cities. As mentioned in Subsection 5.1 the socioeconomic characteristics are slightly better in City 1 . The exit rates to work are higher for younger individuals and UI recipients who collected UI benefits before. This indicates that job search experience is more important than stigmatization due to having experienced earlier UI spells. The remaining covariate effects relate to the UI benefits. Individuals who only receive benefits for a few days per week have a lower transition rate to work. These individuals only lost a low number of working hours, because either they worked a limited number of hours or they stayed employed for the remaining hours. In the first case these individuals are again most likely searching for part-time jobs as they probably prefer these over full-time jobs. Either finding a full-time job is easier than finding a part-time job, or individuals preferring part-time jobs have some unobserved characteristics which decrease the re-employment probabilities. If the UI recipients are still employed for the remaining hours, job search is more complicated and thus again exit rates are lower. ${ }^{13}$

Table 6 shows the parameter estimates of separate Mixed Proportional Hazard rate models for the treatment and control group. This allows for full interaction between the treatment effect on the one hand, and the covariate effects and duration dependence on the other. This means that we allow the treatment effect to be heterogenous: the proportionate effect on the exit rate to work may differ across individuals with different characteristics, ${ }^{14}$ and the effect may also change during the spell of unemployment. By analogy to equation (12) we may write $\theta_{z}(t \mid x, v)=\lambda_{z}(t) \exp \left(x^{\prime} \beta_{z}+v\right)$, where the index $z$ denotes the treatment status $(1$

\footnotetext{
${ }^{13}$ We also estimated the duration model on the so-called "matched sample" (see Subsection 5.2 ). This allows for more elements in $x$. However, the results are very similar.

${ }^{14}$ The nonparametric analyses show that the average effect is zero, but the theoretical analyses suggest that the size of the individual effect depends on the structural parameters, which may differ across individuals.
} 
iff treated). Then the log proportionate treatment effect (or, simply, the treatment effect) $\delta(t, x)$ on the exit rate to work for an individual with characteristics $x, v$ at duration $t$ equals $\log \theta_{1}(t \mid x, v)-\log \theta_{0}(t \mid x, v)$, which equals

$$
\delta(t, x)=\log \lambda_{1}(t)-\log \lambda_{0}(t)+x^{\prime}\left(\beta_{1}-\beta_{0}\right)
$$

In the estimation we allow the unobserved heterogeneity distributions to be different between the groups, although there is no reason to suspect they are different. Invariably, unobserved heterogeneity is estimated to be absent in both groups, and the reported results are conditional on absence of unobserved heterogeneity. We have 12 additional parameters compared to the earlier duration model. Since the Likelihood Ratio test statistic has a value of 7.7 , we accept the null hypothesis of joint insignificance, which again amounts to insignificance of the treatment effect. A closer look at the parameter estimates learns that the estimated models differ slightly in the duration dependence effects and the effects of being female, age and marital status. The differences in the age and duration dependence effects are particularly interesting for the following reason. Older and longer-term individuals are generally acknowledged to have relatively bad labor market prospects. Now note that these groups benefit somewhat more from C\&M than younger and short-term individuals. This is fully consistent with the theoretical analysis, which predicts that monitoring has a larger effect if the individual's labor market prospects are worse.

We also estimated models where the interaction with the treatment effect is restricted to specific elements in $x$ or to the duration dependence. The results are in agreement to those presented here. The null hypothesis of a zero treatment effect is never rejected, not even for specific subgroups or specific time intervals.

\subsection{Binary outcome analyses concerning exit to work}

Whether an individual has made a transition from unemployment to work or not before the end of the observation window constitutes a binary outcome measure. One may define the corresponding population fraction to be the parameter of interest. For a range of model specifications, a positive treatment effect on the transition rate to work results in a smaller population fraction among the treated than among the untreated.

Of course, the probability to make such a transition is lower for individuals who have entered unemployment just before the end of that period. However, due to the randomization, the moment of entry into unemployment is independent of the treatment status. Within both groups we have an identical distribution of 
entry dates across individuals. A more serious problem is posed by individuals who make a transition to another state (like non-participation) before the end of the observation window, i.e. who have durations until exit to work that are right-censored due to exit to other destinations. In general it does not make sense to allocate these individuals to the group that made the transition to work, or to the group that has not made that transition, or to drop them completely from the analysis. This is a disadvantage of using a binary approach in case of duration data. ${ }^{15}$ Here we deal with this problem by performing tests under various assumptions concerning such individuals.

Within each of the two groups, the number of individuals who make a transition from unemployment to work follows a binomial distribution. We test for equality of the parameters of this distribution by using the familiar asymptotic chi-square test (see e.g. Mood, Graybill and Boes, 1986). The test statistic has the value 1.04, which is smaller than the corresponding $95 \%$ critical value of 3.84 of the chi-square(1) distribution. In case we add the individuals who make a transition to non-work to the individuals who make a transition to work, then the test statistic value equals 1.05. In sum, these tests accept the null hypothesis that the treatment is ineffective. The same conclusion follows from probit analyses on whether an individual has made a transition from unemployment to work before the end of the observation window, correcting for $x$ variables.

We also estimate probit models for whether or not an exit to work is observed within some fixed period after the beginning of the spell. This approach can be thought of as being in between the duration analysis and the above binary outcome analysis. However, this approach also focuses on a binary outcome, and, as before, it is difficult to reconcile with short right-censored spells. Here, we deal with this by simply excluding spells that are right-censored within the fixed period. For a fixed period of 12 weeks the parameter estimates are presented in Table 7 . We exclude 24 observations due to early right-censoring. The parameter estimates turn out to be insensitive to decreases in the length of the fixed period. However, beyond 12 weeks the number of "early" right-censored spells increases quickly with the length of the fixed period. In any case, the estimated effect of $\mathrm{C} \& \mathrm{M}$ is invariably positive and insignificant. The estimated covariate effects do not differ much from those presented in the previous subsection.

\footnotetext{
${ }^{15}$ Another disadvantage is that a lot of information is not exploited. The advantage is that no model specification is needed.
} 


\subsection{Cost-benefits analysis of the policy}

We now estimate the net return of the policy. As noted in Subsection 2.2, the UI agency receives a lump sum payment at the beginning of the individual's unemployment spell, as a refund for the costs of C\&M. The amount of this payment is supposed to cover the expected expenses of $\mathrm{C} \& \mathrm{M}$, so it can be regarded as a part of the average costs of the C\&M policy, where the mean benefits payments to $\mathrm{C} \& \mathrm{M}$ recipients constitute the remaining part of the average costs of this policy. The average costs of a system without $\mathrm{C} \& \mathrm{M}$ then consist of $(i)$ the mean benefits payments to individuals who do not receive C\&M and (ii) the expectation of the costs that the agency has to make every 4 weeks to determine whether the individual is still eligible for UI benefits (recall that with C\&M this check is carried out during the C\&M meeting). ${ }^{16}$ Obviously, to calculate the net expected return of the policy, we need an estimate of the mean unemployment duration, which in turn requires the estimation of the duration distribution. To proceed, we may assume that $(i)$ there is no duration dependence after four months, $(i i)$ the effect of $\mathrm{C} \& \mathrm{M}$ is constant during the spell of unemployment (including the period after 6 months, after the final C\&M meeting) and (iii) the benefits level remains constant during unemployment. Under these strong "extrapolation" assumptions, the net expected return, averaged over all individuals in the inflow, is estimated to equal 1990 guilders (with a standard error, computed using the delta method, of 5124 guilders). ${ }^{17}$

However, the extrapolation assumptions are arbitrary and they have a large effect on the outcome. For example, if we replace the second assumption by the assumption that there is no treatment effect after 6 months, then the net expected return is estimated to equal 124 guilders (standard error 633 guilders). We therefore adopt an alternative approach, where we estimate the net expected return in some given duration interval $(0, T)$, as a function of $T$. If $T$ is smaller than the length of the observation period, we do not have to make extrapolation assumptions. We compute, for each individual in the data, the net expected return for each $T$ between 0 and 20 weeks (the observation period). ${ }^{18}$ Figure 3 depicts the

\footnotetext{
${ }^{16}$ We thus neglect some important indirect costs and returns, such as the overhead costs of the local UI agency, additional tax payments over post-unemployment earnings, and spillover effects for example due to displacement of other workers.

${ }^{17}$ Publication of the values of the determinants of these numbers is prohibited.

${ }^{18}$ Let $c_{a}$ and $b$ denote the lump sum payment at the beginning of the spell and the benefits level, respectively. At durations $\tau_{1}, \tau_{2}, \ldots$ the agency determines at a cost $c_{b}$ whether the individual is still eligible for UI benefits. Further, let $f_{1}$ and $f_{0}$ denote the duration densities within the treatment and control populations, respectively, and let $F_{i}$ denote the corresponding distribution functions. The net expected return until $T$ equals
} 
minus net expected return in $(0, T)$ as a function of $T$ in the observation period. The scale of the vertical axis is chosen with an eye on the fact that the mean value of the benefits level $b$ among the inflow into UI is about 3700 guilders per month. (Note that the cost of provision of C\&M is relatively low in comparison to this.) For $T$ exceeding 19 weeks and 4 days, the net expected return is positive. Because UI recipients are entitled to benefits for at least 6 months, and the UI agency provides C\&M for a period of 6 months, C\&M can be considered as cost effective. Note that most individuals are entitled for more than 6 months of UI benefits, and the effect of C\&M does not have to disappear completely after 6 months (for example, recall that $\mathrm{C} \& \mathrm{M}$ also includes advice on writing application letters). From a cost-benefit point of view, C\&M can be considered as rather successful. However, the confidence interval becomes large when $T$ increases up to 6 months (see Figure 3), and we cannot reject the hypothesis that the net expected return is zero.

\subsection{Search methods}

In this subsection we present a formal analysis of the data from the follow-up survey on the job search channels used by the individuals. We perform analyses both for the full sample of respondents and for the matched sample, but we only report those for the full sample, because of the small size of the other sample (there are no important differences in the results).

We distinguish between formal and informal job search channels and estimate a bivariate ordered probit model for the number of formal and informal job search channels used. Let $y_{1}^{*}$ and $y_{2}^{*}$ be latent variables specified as

$$
y_{i}^{*}=x^{\prime} \beta_{i}+\varepsilon_{i} \quad i=1,2
$$

The observed variable $y_{i}$ indicating the number of methods used along channel $i$ is then assumed to satisfy $y_{i}=k$ iff $a_{k-1}<y_{i}^{*} \leq a_{k}$, for $k=1,2, \ldots, \bar{k}$, where $a_{0}=-\infty$ and $a_{\bar{k}}=\infty$. Finally, we let $\varepsilon_{1}$ and $\varepsilon_{2}$ both be standard normally distributed with correlation $\rho$. Note that the means and variances of a general bivariate normal distribution would be unidentified. The 3 formal job search channels between which we distinguish are: (1) public employment office / local UI

$-c_{a}-\int_{0}^{T} b t\left(f_{1}(t)-f_{0}(t)\right) d t-b T\left(\left(1-F_{1}(T)\right)-\left(1-F_{0}(T)\right)\right)+\sum_{i=1,2, \ldots} c_{b}\left(1-F_{0}\left(\tau_{i}\right)\right) I\left(\tau_{i}<T\right)$ where $I\left(\tau_{i}<T\right)=1$ if $\tau_{i}<T$ and is 0 otherwise. 
agency, (2) commercial employment agencies and (3) personnel advertisements. We distinguish between 2 informal job search channels: (1) open application letters and (2) job search through friends and relatives.

In Table 8 we present the estimation results. Clearly, C\&M stimulates the use of formal search methods at the expense of informal methods. So unemployed workers who receive $\mathrm{C} \& \mathrm{M}$ substitute effort along the informal channel into effort along the formal channel. This is in agreement to the theoretical analysis in Subsection 3.3. ${ }^{19}$ Note that, as in the empirical literature, older individuals use more formal channels than younger individuals.

The theoretical results also predict that effort substitution is strongest for the individuals with the best labor market opportunities. We empirically investigate this by allowing the C\&M effects in the above model to depend on the log age of the respondent. ${ }^{20}$ The estimation results (not reported here) show that the the positive C\&M effect on the number of formal channels is weaker for older individuals, and that the negative C\&M effect on the number of informal channels is also weaker for them. Thus, older individuals use more formal channels anyway, and they do not substitute as much towards formal channels as younger individuals do. This is completely in agreement with our theoretical predictions.

\section{An integrated view}

In this section we combine the empirical evidence based on the administrative data and the survey data of the social experiment with the theoretical insights that we obtained and the results in the empirical literature on active labor market policies, in order to enhance our understanding of the economic behavior of the unemployed individuals. This enables us to extrapolate our empirical results and to draw conclusions about a wider class of labor market policies that concern job search assistance and monitoring of search effort.

In the theoretical analysis, job search assistance is represented by an increase

\footnotetext{
${ }^{19}$ Keeley and Robins (1985) use non-experimental data on actual choices of search channels by respondents to a multi-purpose survey. The data contain indicators of the amount of monitoring and channel use across respondents. Their results do not agree to a high degree to the theoretical predictions, but obviously their estimates may be strongly affected by self-selection bias concerning the amount of monitoring and the search channel choice.

${ }^{20}$ Alternatively, one could interact the $\mathrm{C} \& \mathrm{M}$ effects with the estimated systematic component $\exp \left(x^{\prime} \beta\right)$ of the exit rate to work, since the latter is an indicator of labor market prospects. However, this requires the use of the "matched" sample, which is substantially smaller than the survey sample. Moreover, the most significant estimate in $\beta$ corresponds to the UI benefits level, and it is not obvious that (the effect of) this level captures labor market opportunities.
} 
of the effectiveness of search. The theoretical analysis demonstrates that such an increase leads to an increase of the exit rate to work. The empirical analysis shows that this rate does not depend on whether individuals are subject to the C\&M policy. Therefore, the "counseling" component in this policy does not entail an increase in the effectiveness of search. This is confirmed by the survey evidence, which shows that C\&M does not entail any substantial job search assistance.

According to the theoretical analysis, monitoring of search activities leads to substitution from informal search methods to formal methods. The empirical analysis of the survey data shows that this is exactly what is taking place. The theoretical analysis shows that the sign of the net effect on the exit rate to work is indeterminate. The data tell us that the net effect is zero. We conclude that the "monitoring" component in the C\&M policy is inefficient: the resulting individual behavior is sub-optimal from the individual's point of view, while the exit rate to work does not change.

The previous paragraphs examine counseling and monitoring in isolation from each other. If we examine them jointly then we are led to the same conclusions, although we cannot rule out that counseling leads to a small increase in the exit rate while monitoring leads to an equally small decrease.

Now let us relate this to some results in the empirical literature that uses data from social experiments. First, note that we consider unemployed workers with relatively good labor market prospects, and that the general labor market conditions at the time the data were collected were very favorable by Dutch standards. According to our theoretical results and the empirical literature on search channels, the informal channel is more important if labor market prospects are good. In that case, channel substitution is relatively easy, and, as a result, monitoring is ineffective. Our empirical results on the interaction effect of age and treatment status on the choice of search channels also confirm this.

Ashenfelter, Ashmore and Deschênes (1999) analyze the effect of a system with more intensive monitoring on labor market outcomes of U.S. UI recipients. They find no significant effect on the exit rate to employment (they also focus on other outcome measures, like UI payments and wages). As the U.S. labor market is characterized by lower unemployment durations than the Dutch labor market in general, their result is in agreement to our results.

Gorter and Kalb (1996) consider a policy which can be interpreted as coming on top of the C\&M policy we consider; in their case the treatment consists of longer monthly meetings, with more time for job search assistance, and more monitoring. Their data are from The Netherlands in 1989-1990, and their sample of UI recipients includes individuals with Type II-IV profiling outcomes. As 
a result, the average labor market prospects among their sampled individuals are worse than in our case. Their estimated effect on the exit rate to work is twice as large as in our case and almost significant. The difference in magnitude can be explained by two factors. First, their policy entails more substantial job search assistance. Secondly, individuals with worse characteristics, under worse macro-economic conditions, may have less scope for substitution of search methods. In particular, their informal channel may dry up relatively quickly after inflow into unemployment, meaning that the cost of search along the informal channel becomes prohibitively large after a short elapsed duration (Gorter and Kalb, 1996, do not consider the use of different channels in their analysis.) Interestingly, Gorter and Kalb (1996) also find that, at the same time, the rate of job applications is significantly larger among the treated. This is in agreement with both above-mentioned factors. However, remember that the exit rate is not significantly larger. This may mean that a disproportionally large amount of the additional applications result in rejection by the employer. In addition, it should be noted that data on numbers of applications are sometimes unreliable (recall the discussion in Subsection 5.2).

Dolton and O'Neill $(1995,1996)$ also consider job search assistance in combination with increased monitoring, of individuals with on average worse characteristics than we have, in a situation with worse macro-economic conditions (see also White and Lakey, 1992). Specifically, they consider individuals with an elapsed duration of at least 6 months, in the U.K. in the early 1990s. ${ }^{21}$ They find a positive effect on the exit rate to work and on the job offer arrival rate, but a zero effect on the reservation wage (they do not distinguish between different search channels). According to our theoretical analysis, this can only be explained by a positive effect of the job search assistance on the job offer arrival rate (which leads to a higher reservation wage) in combination with an effect of the monitoring on the arrival rate (which leads to a lower reservation wage) ${ }^{22}$ This reinforces the conclusions drawn above from Gorter and Kalb (1996).

Meyer (1995) provides a survey of U.S. social experiments concerning job search assistance programs. These programs include job search workshops of sev-

\footnotetext{
${ }^{21}$ This "Restart" program consists of six-monthly compulsory meetings during which advice on job search is provided and unemployed workers are placed in contact with employers and training agencies. The first meeting takes place after 6 months. Unemployment benefits are reduced or suspended if individuals do not participate in the program or do not search for jobs sufficiently hard.

${ }^{22}$ If job search assistance would have a zero effect on the arrival rate while the exit rate changes then the reservation wage should decrease. If monitoring would have a zero effect on the arrival rate while the exit rate increases then the reservation wage should increase.
} 
eral hours or even days. It turns out that the effect on the exit rate to work increases in the intensity of the assistance. The decrease in the duration of UI dependence ranges from around half a week to more than three weeks. The surveys of Björklund and Regnér (1996), Fay (1996), and Heckman, LaLonde and Smith (1999) also report positive effects of intensive job search assistance on the exit rate to work.

We conclude that the more intensive the job search assistance, the higher the exit rate to work. ${ }^{23}$ Also, the worse the labor market prospects (individual or macro-economic), the larger the effect of monitoring on the exit rate to work.

\section{Conclusions}

Low-intensity job search assistance programs, like the counseling component of the C\&M policy studied in the present paper, are useless. High-intensity job search assistance programs have a positive effect on the exit rate to work. Monitoring of relatively well qualified individuals in favorable macroeconomic conditions is inefficient and merely leads to substitution of search methods. Individuals with worse prospects have less scope for substitution, and monitoring of their search activity may lead to an increase in the exit rate to work. We conclude that (1) the more intensive the job search assistance, the higher the exit rate to work, and (2) the worse the labor market prospects (individual or macro-economic), the larger the effect of monitoring on the exit rate to work.

In OECD countries, monitoring of unemployment benefits recipients has become an increasingly important policy tool (see OECD, 2000, for a survey). Often, eligibility criteria are harsher, and monitoring is more intense, if the individual has relatively favorable labor market opportunities (see also Abbring, Van den Berg and Van Ours, 1997, and Van den Berg, Van der Klaauw and Van Ours, 1998, and references therein). The results in the present paper show that it makes more sense to focus monitoring on individuals with worse opportunities.

Finally, as a methodological conclusion, the results from the different studies based on social experiments are mutually consistent to a very high degree. This compares favorably to the literature in which reduced-form models are estimated from non-experimental data (see Heckman, LaLonde and Smith, 1999 for a survey). In addition, the results from the experiments can be understood well from

\footnotetext{
${ }^{23}$ Fougère, Pradel and Roger (1998) demonstrate in a structural empirical analysis that a public employment agency that matches employers and employees reduces search costs and increases the job offer arrival rate. The unemployment durations of the individuals in their data are relatively large. So their evidence is consistent to ours.
} 
a theoretical point of view. 


\section{References}

Abbring, J.H., G.J. van den Berg and J.C. van Ours (1997), The effect of unemployment insurance sanctions on the transition rate from unemployment to employment, Working Paper, Tinbergen Institute, Amsterdam.

Albrecht, J.W., B. Holmlund and H. Lang (1991), Comparative statistics in dynamic programming models with an application to job search, Journal of Economic Dynamics and Control 15, 755-769.

Ashenfelter, O., D. Ashmore and O. Deschênes (1999), Do unemployment insurance recipients actively seek work? Randomized trials in four U.S. states, Working Paper, NBER, Cambridge.

Bean, C.R. (1994), European unemployment: A survey, Journal of Economic Literature 32, 573-619.

Björklund, A. and H. Regnér (1996), Experimental evaluation of European labour market policy, in G. Schmid et al. (eds.), International Handbook of Labour Market Policy and Evaluation, Edward Elgar, Aldershot.

Blau, D.M. and P.K. Robins (1990), Job search outcomes for the employed and unemployed, Journal of Political Economy 98, 637-655.

Card, D. and P.K. Robins (1998), Do financial incentives encourage welfare recipients to work? Evidence from a randomized evaluation of the self-sufficiency project, Research in Labor Economics 17, 1-56.

Dewatripont, M., I. Jewitt and J. Tirole (2000), Multitask agency problems: Focus and task clustering, European Economic Review 44, 869-877.

Dolton, P. and D. O'Neill (1995), The impact of Restart on reservation wages and long-term unemployment, Oxford Bulletin of Economics and Statistics 57, 451-470.

Dolton, P. and D. O'Neill (1996), Unemployment duration and the Restart effect: Some experimental evidence, Economic Journal 106, 387-400.

Eberwein, C., J.C. Ham and R.J. LaLonde (1997), The impact of being offered and receiving classroom training on the employment histories of disadvantaged women: Evidence from experimental data, Review of Economic Studies 64, $655-682$.

Fay, R.G. (1996), Enhancing the effectiveness of active labour market policies: Evidence from programme evaluations in OECD countries, Working paper, OECD, Paris. 
Fougère, D., J. Pradel and M. Roger (1998), Public employment offices and the transition rate from unemployment to employment, Working paper, CRESTINSEE, Paris.

Gorter, C. and G.R.J. Kalb (1996), Estimating the effect of counseling and monitoring the unemployed using a job search model, Journal of Human Resources $31,590-610$.

Heckman, J.J., R.J. LaLonde and J.A. Smith (1999), The economics and econometrics of active labor market programs, in O. Ashenfelter and D. Card (eds.), Handbook of Labor Economics, Volume 3, North-Holland, Amsterdam.

Holzer, H. (1988), Search method use by the unemployed youth, Journal of Labor Economics 6, 1-20.

Holmström, B. and P. Milgrom, (1991), Multitask principal-agent analyses: Incentive contracts, asset ownership, and job design, Journal of Law, Economics and Organization 7, 24-52.

Keeley, M.C. and P.K. Robins (1985), Government programs, job search requirements, and the duration of unemployment, Journal of Labor Economics 3, $337-362$.

Koning, P., G.J. van den Berg and G. Ridder (1997), A structural analysis of job search methods and subsequent wages, Working Paper, Tinbergen Institute, Amsterdam.

LaLonde, R.J. (1986), Evaluating the econometric evaluations of training programs with experimental data, American Economic Review 76, 604-620.

Lancaster, T. (1990), The Econometric Analysis of Transition Data, Cambridge University Press, Cambridge.

Layard, R., S. Nickell and R. Jackman (1991), Unemployment: Macroeconomic Performance on the Labour Market, Oxford University Press, Oxford.

Lindeboom, M., J.C. van Ours and G. Renes (1994), Matching employers and workers: An empirical analysis on the effectiveness of search, Oxford Economic Papers 46, 45-67.

LISV (1998), Kroniek van de sociale verzekering 1998, wetgeving en volumeontwikkeling in historisch perspectief (In Dutch), Landelijk Instituut Sociale Verzekeringen, Amsterdam.

Meyer, B.D. (1995), Lessons from the U.S. unemployment insurance experiments, Journal of Economic Literature 33, 91-131. 
Milgrom, P. and J. Roberts (1992), Economics, Organization and Management, Prentice Hall, London.

Montgomery, J.D. (1991), Social networks and labor-market outcomes: Towards an economic analysis, American Economic Review 81, 1408-1418.

Mood, A.M., F.A. Graybill and D.C. Boes (1986), Introduction to the theory of statistics, McGraw-Hill, Singapore.

Mortensen, D.T. (1986), Job search and labor market analysis, in O. Ashenfelter and R. Layard (eds.), Handbook of Labor Economics, Volume 2, NorthHolland, Amsterdam.

Mortensen, D.T. and C.A. Pissarides, (1999), New developments in models of search in the labor market, in O. Ashenfelter and D. Card (eds.), Handbook of Labor Economics, Volume 3, North Holland, Amsterdam.

Mortensen, D.T. and T. Vishwanath (1994), Personal contracts and earnings, Labour Economics 1, 187-201.

OECD (2000), Employment Outlook 2000, OECD, Paris.

Prendergast, C. (1999), The provision of incentives in firms, Journal of Economic Literature 37, 7-63.

Regioplan (1999), Experimentele effectmeting A\&C (in Dutch), Working Paper, Regioplan, Amsterdam.

Sabatier, M. (2001), Job search with endogenous search methods: An application on young unemployment spells in France, Working Paper, University of Auvergne.

Van den Berg, G.J. (1990), Nonstationarity in job search theory, Review of Economic Studies 57, 255-277.

Van den Berg, G.J. (1994), The effects of changes of the job offer arrival rate on the duration of unemployment, Journal of Labor Economics 12, 478-498.

Van den Berg, G.J., B. van der Klaauw and J.C. van Ours (1998), Punitive sanctions and the transition rate from welfare to work, Working Paper, Tinbergen Institute, Amsterdam.

White, M. and J. Lakey (1992), The Restart effect: Does active labour market policy reduce unemployment?, Policy Studies Institute, London. 


\section{Appendix}

\section{Appendix 1 Profiling / classification of unemployed work- ers}

Upon the moment of application for benefits, an individual is classified into one of four "types" ${ }^{24}$ The classification is used to tune the services of the unemployment agency to the needs of the worker, with the main purpose to decrease the expected duration of benefits payment. The type may change during the spell of unemployment.

The classification of an individual is supposed to capture his "distance to the labor market", which in turn is supposed to be related to his expected duration of unemployment. The unemployed workers who are considered to have the highest re-employment probabilities are classified as Type I individuals, while the Type IV individuals have the highest expected unemployment durations. As mentioned in the main text, Type I individuals are expected to have sufficient skills to find work. The Type II and III individuals are considered not to have the skills to find work without any assistance. Therefore, these are provided with training and schooling. The Type IV individuals are the most disadvantaged and need more care. These individuals are often unable to work or not obliged to search for work (lone parents with dependent children, drug addicts, etc.).

The scheme which is used to determine the type of the worker consists of three steps. It is important to keep in mind that, ultimately, the classification does not only depend on objective measures, but also on the (subjective) opinion of the case worker or official of the unemployment agency.

In the first step it is determined whether or not the individual is actually unemployed and a member of the labor force. A worker is a member of the labor force if he is ( $i$ ) legally allowed to stay in The Netherlands, (ii) between 16 and 65 years old, and (iii) not disabled. Furthermore, in this step some unemployed workers who do not have a formal obligation to search for work actively, are classified as Type IV. This are individuals who meet one of the following criteria: (i) being older than 57.5 years, (ii) having a dependent child under 5 years old, (iii) being unemployed due to weather conditions, and (iv) working less due to a reduction of the hours within the full-time working week.

\footnotetext{
${ }^{24}$ This classification is not restricted to unemployed individuals receiving UI benefits. Everyone who registers is classified into the same four types, including those who claim welfare benefits, and even employed workers who register because their contract expires in the near future, they work part-time and look for a full-time job, or they are just looking for another job.
} 
The second step determines a score for the unemployed worker. This score is based on three items and is expected to be a measure of the individual labor market prospects. For each of the three items, which we discuss below, the unemployed workers get a score of 1, 4, 6 or 8 points. The first item on which the unemployed workers are evaluated is their profession. Based on some measure of the tightness of the labor market for individuals with the same profession, the score on the first item is determined. In this measure also the age of the unemployed worker and the geographical region in which he lives are taken into account. More points are given for better labor market prospects. In case an unemployed worker has more than one profession, the profession with the highest score is used.

The second item concerns eduction and work experience. We distinguish three groups of unemployed workers, low-skilled job losers, high-skilled job losers and school leavers. ${ }^{25}$ School leavers are individuals who entered unemployment immediately after full-time education. The number of points they get depends on their highest completed education. School leavers who dropped out of high school before completing the education get 6 point if they are capable of performing lowqualified work, otherwise they only get 1 point. School leavers who did not drop out early get 8 points if they completed an additional education after high school, 6 point for completing a high school education of 5 or 6 years and 4 point for finishing a 4-year high school education. The low-skilled job losers get 4 points if they did not work in the past 3 years, 6 point if they have some work experience in the past 3 years, but not in the last years and they get 8 points if there work experience is recent. The points for the high-skilled workers with a relevant education or more than 3 years of work experienced are distributed in the same way. Finally, high-skilled workers with less than 3 years of work experience and without a relevant education get 6 points if their work experience is recent, 4 points if they have worked in the past 3 years, but not in the past years and in any other case they get only 1 point.

The third item concerns some other characteristics of the unemployed worker. The employee of the unemployment agency has to judge the individual on job search behavior, flexibility, language skills, presentation skills and responsibility. He has to decide on how the unemployed workers scores on the combination of these skills and gives $8,6,4$ or 1 points accordingly.

In the third step it is checked if there are any serious impediments to work

\footnotetext{
${ }^{25}$ Here, high and low-skilled does not depend on the level of education, but on the type of work these unemployed workers have performed. In general, an unemployed worker who performed high-skilled work is also expected to search for high-skilled work regardless of his education.
} 
for the unemployed worker. These impediments can be psychological, physical or social. A common occurring reason of impediments is drug or alcohol addiction, but also taking care of sick family members can be a possible reason. The unemployed workers who have such impediments are classified as Type IV. If there are no impediments, the classification is based on the number of points scored in step two. The individuals who score 18 points or more are the Type I unemployed workers. Unemployed workers who score less than 18 points have to show up for a next meeting. During this meeting it is decided more informally whether the unemployed worker is of Type II or Type III.

\section{Appendix 2 Proof of Proposition 1}

To derive $d \theta / d \lambda_{1}$ we only need to consider the equations (7) and (8). Since we are only interested in the sign of $d \theta / d \lambda_{1}$, we may normalize $c_{0}=1$ without loss of generality. Define a new parameter $\tilde{\lambda}$ as follows,

$$
\widetilde{\lambda}:=\left(\lambda_{1}^{3}+\lambda_{2}^{3}\right)^{1 / 3}
$$

After substituting $F:=F_{1}=F_{2}, c_{0}=1$, and the above $\tilde{\lambda}$ into the equations (7) and (8), we obtain

$$
\begin{gathered}
\phi=b+\left(\frac{3}{16}\right)^{1 / 3}\left(\frac{\tilde{\lambda} Q(\phi)}{\rho}\right)^{2} \\
\theta=(3 / 2)^{1 / 3} \bar{F}(\phi) \widetilde{\lambda}^{2} Q(\phi) / \rho
\end{gathered}
$$

It is readily verified that these are equations for the reservation wage and the exit rate out of unemployment in a model with a single search channel (with arrival rate $\tilde{\lambda} s$ and search cost function equal to $\left.(1 / 12)^{1 / 3} s^{2}\right)$. The derivative of $\theta$ with respect to $\lambda_{1}$ has the same sign as the derivative of $\theta$ with respect to the parameter $\tilde{\lambda}$ defined above. So, the assumption that $F_{1}=F_{2}$ allows us to simplify the model by reformulating it as a model with a single channel. We can simplify this further by defining $\lambda:=(3 / 2)^{1 / 3}(\widetilde{\lambda})^{2}$ and examining $d \theta / d \lambda$.

By totally differentiating equation (13) we obtain,

$$
\frac{d \phi}{d \lambda}=\frac{(Q(\phi))^{2}}{2 \rho^{2}+2 \lambda Q(\phi) \bar{F}(\phi)}>0
$$

By substituting this into $d \theta / d \lambda$ we obtain that the latter has the same sign as

$$
2 \rho^{2} \bar{F}(\phi)+\lambda Q(\phi)\left((\bar{F}(\phi))^{2}-f(\phi) Q(\phi)\right)
$$


where $f$ is the density of $F$. Recall that $0<\bar{F}(\phi)<1$. Equation (13) states that $2 \rho^{2}=\lambda(Q(\phi))^{2} /(\phi-b)$. By substituting this into the the above expression we obtain that $d \theta / d \lambda>0$ if and only if

$$
\frac{Q(\phi) \bar{F}(\phi)}{\phi-b}>f(\phi) Q(\phi)-(\bar{F}(\phi))^{2}
$$

As $\phi>b$, sufficient for this is that

$$
\frac{Q(\phi) \bar{F}(\phi)}{\phi}>f(\phi) Q(\phi)-(\bar{F}(\phi))^{2}
$$

Now define

$$
\mu(x)=\mathrm{E}(w \mid w>x)
$$

which is the conditional mean function associated with $F$. There holds that

$$
\mu(x)=\frac{Q(x)}{\bar{F}(x)}+x
$$

By substituting this for $Q$ in (15) we obtain

$$
\frac{\mu(\phi)-\phi}{\phi}>\frac{f(\phi)}{\bar{F}(\phi)}(\mu(\phi)-\phi)-1
$$

Note that the right-hand side equals $\mu^{\prime}(\phi)-1$. Consequently, the inequality can be written as

$$
\frac{d \log \mu(x)}{d \log x}<1 \quad \text { at } x=\phi
$$

As is shown in Van den Berg (1994), Condition A implies that this inequality is satisfied for all $x$ in the support of $F$. This completes the result for $d \theta / d \lambda_{1}>0$.

To show that $d s_{1} / d \lambda_{1}>0$ we need to use the original model equations in the main text. This result then follows from straightforward differentiation and elaboration. The signs of the other derivatives mentioned in Proposition 1 follow trivially. 


\begin{tabular}{|l|c|}
\hline \multicolumn{2}{|l|}{ Individual characteristics } \\
\hline Received C\&M & $52 \%$ \\
Control group & $48 \%$ \\
Male & $60 \%$ \\
Female & $40 \%$ \\
Collected UI before & $25 \%$ \\
New client & $75 \%$ \\
Single & $43 \%$ \\
Not single & $57 \%$ \\
City 1 & $39 \%$ \\
City 2 & $61 \%$ \\
Age (in years) & 36 \\
\end{tabular}

Table 1: Summary statistics for the administrative data set. 


\begin{tabular}{|l|cc|}
\hline intercept & 0.19 & $(1.22)$ \\
\hline \hline \multicolumn{3}{|c|}{ Individual characteristics } \\
\hline Female & 0.019 & $(0.15)$ \\
log Age & -0.094 & $(0.30)$ \\
Collected UI before & -0.19 & $(0.15)$ \\
Not single & -0.29 & $(0.14)$ \\
\# days per week UI & -0.028 & $(0.10)$ \\
log Benefits per day & 0.096 & $(0.23)$ \\
City 2 & 0.055 & $(0.14)$ \\
\hline \hline Log likelihood & \multicolumn{2}{|c|}{-269.23} \\
\# observations & 394 \\
\hline
\end{tabular}

Explanatory note: Standard errors in parentheses.

Table 2: Estimation results of the probit model for being assigned to the treatment group (1) or to the control group (0).

\begin{tabular}{|l|c|}
\hline Agreements on the number of job applications & 64 \\
Providing information about my UI benefits & 61 \\
Discussing my labor market history and education & 52 \\
Checking my job applications & 50 \\
Discussing labor market prospects & 46 \\
Suggestions concerning applications & 33 \\
Written confirmation of agreements & 24 \\
Offering training and schooling & 10 \\
Other topics & 1 \\
\hline \hline Number of respondents & 78 \\
\hline
\end{tabular}

Table 3: Number of respondents in the treatment group who claim that a certain activity is part of the C\&M meetings. 


\begin{tabular}{|l|cc|}
\hline & $\begin{array}{c}\text { Treatment } \\
\text { group }\end{array}$ & $\begin{array}{c}\text { Control } \\
\text { group }\end{array}$ \\
\hline \hline \multicolumn{2}{|l|}{ Formal job search channels } & \\
\hline Public employment office & 17 & 9 \\
Commercial employment agencies & 22 & 18 \\
Local UI agency & 3 & 0 \\
Job advertisements & 28 & 35 \\
\hline Total & 42 & 40 \\
\hline \hline \multicolumn{2}{|l|}{ Informal search channels } & 21 \\
\hline Open application letters & 10 & 28 \\
Friends and relatives & 23 & 38 \\
\hline Total & 44 & 48 \\
\hline \hline Number of respondents &
\end{tabular}

Explanatory note: Total is the total number of respondents who used at least one of the job search channels (formal or informal) listed above it.

Table 4: Job search channels used in the treatment and control group. 


\begin{tabular}{|c|c|c|}
\hline & \multicolumn{2}{|c|}{ Exit rate to work } \\
\hline \multicolumn{3}{|l|}{ Treatment effect } \\
\hline$\delta$ & 0.063 & $(0.15)$ \\
\hline \multicolumn{3}{|l|}{ Intercept } \\
\hline $\bar{v}$ & -26.4 & $(12.4)$ \\
\hline \multicolumn{3}{|l|}{ Duration dependence } \\
\hline$\lambda_{1}$ & 0 & \\
\hline$\lambda_{2}$ & 0.50 & $(0.19)$ \\
\hline$\lambda_{3}$ & 0.20 & $(0.22)$ \\
\hline$\lambda_{4}$ & 0.076 & $(0.25)$ \\
\hline$\lambda_{5}$ & -0.39 & $(0.40)$ \\
\hline \multicolumn{3}{|l|}{ Individual characteristics } \\
\hline Female & -0.0072 & $(0.17)$ \\
\hline $\log$ Age & -0.56 & $(0.36)$ \\
\hline Collected UI before & 0.25 & $(0.17)$ \\
\hline Not single & -0.011 & $(0.16)$ \\
\hline Number of days per week UI & 0.19 & $(0.14)$ \\
\hline log Benefits per day & 9.56 & $(4.85)$ \\
\hline log Benefits per day (squared) & -0.94 & $(0.48)$ \\
\hline City 2 & -0.20 & $(0.16)$ \\
\hline Log likelihood & \multicolumn{2}{|c|}{-792.17} \\
\hline Number of observations & \multicolumn{2}{|c|}{394} \\
\hline
\end{tabular}

Explanatory note: Standard errors in parentheses.

Table 5: Estimation results for the basic duration model. 


\begin{tabular}{|c|c|c|c|c|}
\hline \multirow{2}{*}{ Intercept } & \multicolumn{2}{|c|}{$\begin{array}{l}\text { Exit rate to work } \\
\text { in treatment group }\end{array}$} & \multicolumn{2}{|c|}{$\begin{array}{l}\text { Exit rate to work } \\
\text { in control group }\end{array}$} \\
\hline & & & & \\
\hline$v$ & -22.7 & $(15.5)$ & -34.8 & $(21.2)$ \\
\hline \multicolumn{5}{|l|}{ Duration dependence } \\
\hline$\lambda_{1}$ & 0 & & 0 & \\
\hline$\lambda_{2}$ & 0.59 & $(0.26)$ & 0.43 & $(0.27)$ \\
\hline$\lambda_{3}$ & 0.42 & $(0.30)$ & -0.0093 & $(0.33)$ \\
\hline$\lambda_{4}$ & 0.24 & $(0.34)$ & -0.041 & $(0.37)$ \\
\hline$\lambda_{5}$ & -0.27 & $(0.49)$ & -0.50 & $(0.68)$ \\
\hline \multicolumn{5}{|l|}{ Individual characteristics } \\
\hline Female & -0.22 & $(0.25)$ & 0.14 & $(0.24)$ \\
\hline $\log$ Age & -0.30 & $(0.51)$ & -0.72 & $(0.52)$ \\
\hline Collected UI before & 0.34 & $(0.23)$ & 0.14 & $(0.25)$ \\
\hline Not single & -0.25 & $(0.23)$ & 0.22 & $(0.24)$ \\
\hline Number of days per week UI & 0.15 & $(0.18)$ & 0.19 & $(0.24)$ \\
\hline log Benefits per day & 8.14 & $(6.05)$ & 12.7 & $(8.34)$ \\
\hline log Benefits per day (squared) & -0.82 & $(0.60)$ & -1.22 & $(0.81)$ \\
\hline City 2 & -0.33 & $(0.23)$ & -0.11 & $(0.24)$ \\
\hline Log likelihood & \multirow{2}{*}{\multicolumn{2}{|c|}{$\begin{array}{c}-428.96 \\
205\end{array}$}} & \multirow{2}{*}{\multicolumn{2}{|c|}{$\begin{array}{c}-359.35 \\
189\end{array}$}} \\
\hline Number of observations & & & & \\
\hline
\end{tabular}

Explanatory note: Standard errors in parentheses.

Table 6: Heterogeneous treatment effects: estimation results for separate duration models for the treatment and control groups. 


\begin{tabular}{|c|c|c|}
\hline \multicolumn{3}{|l|}{ Treatment effect } \\
\hline$\delta$ & 0.091 & $(0.14)$ \\
\hline \multicolumn{3}{|l|}{ Intercept } \\
\hline$v$ & -18.2 & $(10.1)$ \\
\hline \multicolumn{3}{|l|}{ Individual characteristics } \\
\hline Female & -0.019 & $(0.15)$ \\
\hline log Age & -0.51 & $(0.33)$ \\
\hline Collected UI before & 0.26 & $(0.16)$ \\
\hline Not single & 0.015 & $(0.15)$ \\
\hline Number of days per week UI & 0.036 & $(0.12)$ \\
\hline $\log$ Benefits per day & 7.75 & $(3.95)$ \\
\hline log Benefits per day (squared) & -0.76 & $(0.39)$ \\
\hline City 2 & -0.23 & $(0.15)$ \\
\hline Log likelihood & \multirow{2}{*}{\multicolumn{2}{|c|}{$\begin{array}{c}-242.40 \\
370\end{array}$}} \\
\hline Number of observations & & \\
\hline
\end{tabular}

Explanatory note: Standard errors in parentheses. Individuals with an unemployment spell that is right-censored within 12 weeks are excluded.

Table 7: Estimation results for probit model for exit to work within 12 weeks. 


\begin{tabular}{|c|c|c|c|c|}
\hline \multirow{2}{*}{ Treatment effect } & \multicolumn{2}{|c|}{$\begin{array}{c}\text { Formal } \\
\text { job search }\end{array}$} & \multicolumn{2}{|c|}{$\begin{array}{c}\text { Informal } \\
\text { job search }\end{array}$} \\
\hline & & & & \\
\hline$\delta$ & 0.34 & $\overline{(0.29)}$ & -0.64 & $(0.28)$ \\
\hline \multicolumn{5}{|c|}{ Individual characteristics } \\
\hline Female & -0.25 & $\overline{(0.29)}$ & -0.21 & $(0.29)$ \\
\hline $\log$ Age & 0.41 & $(0.53)$ & 0.026 & $(0.68)$ \\
\hline Collected UI before & -0.036 & $(0.27)$ & -0.25 & $(0.29)$ \\
\hline City 2 & -0.080 & $(0.27)$ & -0.24 & $(0.31)$ \\
\hline \multicolumn{5}{|l|}{ Correlation } \\
\hline$\rho$ & -0.015 & $(0.19)$ & & \\
\hline \multicolumn{5}{|l|}{ Threshold values } \\
\hline$a_{1}$ & 0.23 & $(1.97)$ & -1.01 & $(2.48)$ \\
\hline$a_{2}$ & 1.65 & $(2.00)$ & 0.59 & $(2.48)$ \\
\hline$a_{3}$ & 2.90 & $(2.01)$ & & \\
\hline Log likelihood & \multicolumn{4}{|c|}{-178.02} \\
\hline Number of observations & \multicolumn{4}{|c|}{87} \\
\hline
\end{tabular}

Explanatory note: Standard errors in parentheses.

Table 8: Estimation results for the bivariate ordered probit model for the number of formal and informal job search channels. 


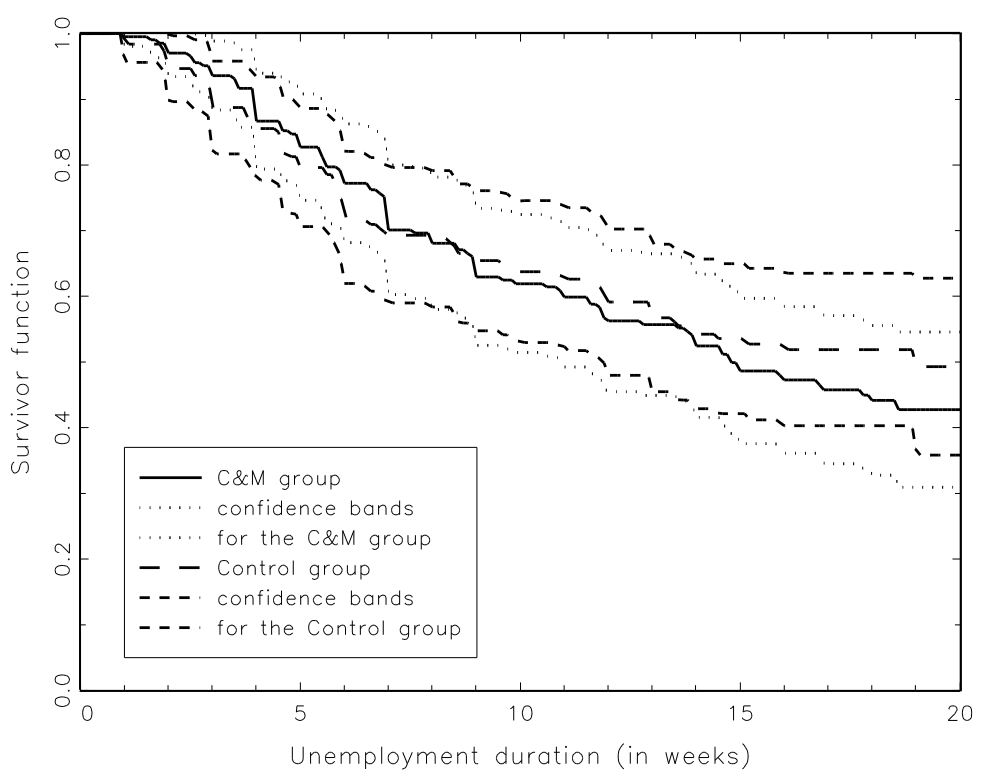

Figure 1: Kaplan-Meier estimates of the survivor function to work for individuals in the treatment and control group.

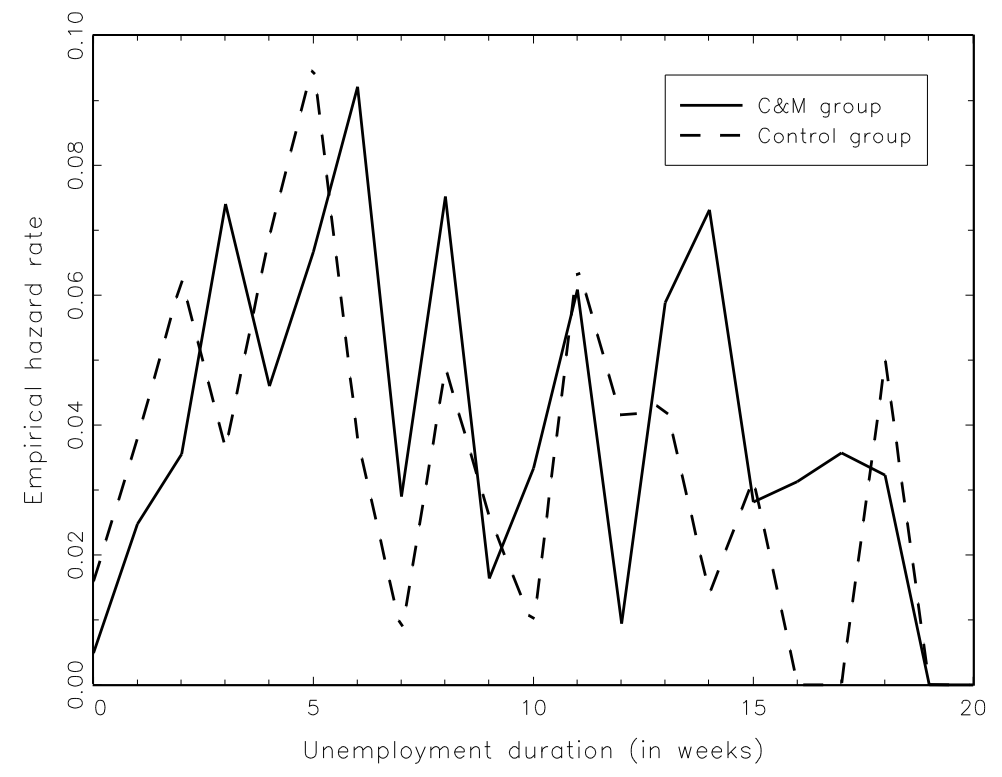

Figure 2: Nonparametric estimates of the exit rate to work for individuals in the treatment and control group. 


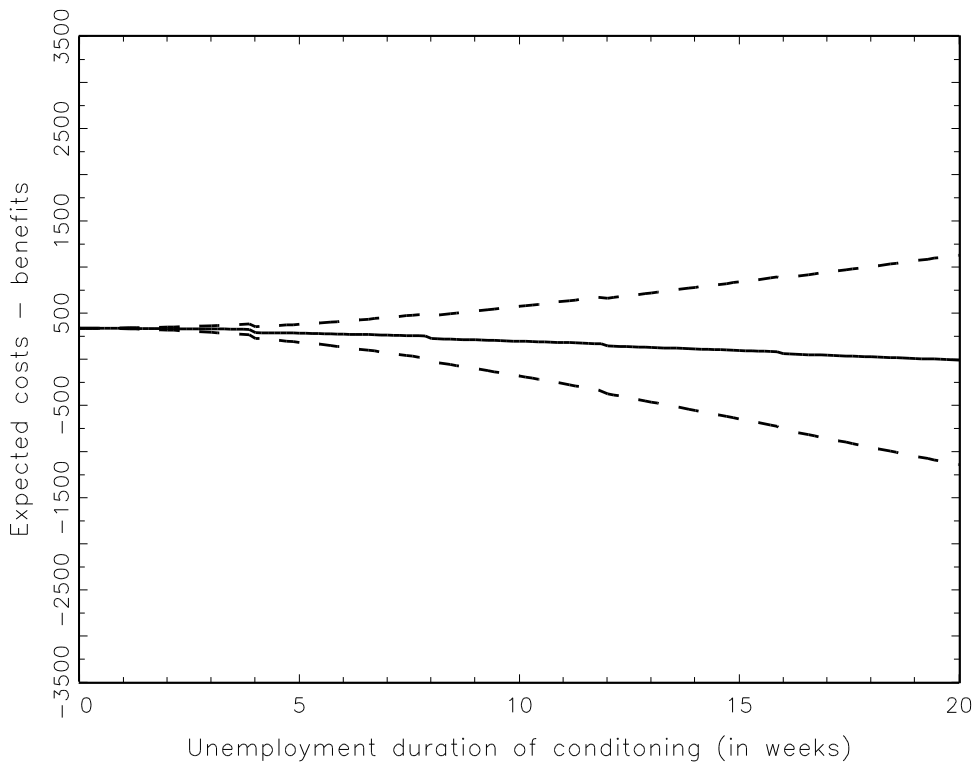

Figure 3: The net expected return in a time interval until a given unemployment duration. The dashed lines represent the pointwise confidence interval. 


\section{IZA Discussion Papers}

\begin{tabular}{|c|c|c|c|c|}
\hline No. & Author(s) & Title & Area & Date \\
\hline 360 & $\begin{array}{l}\text { J. Hansen } \\
\text { M. Lofstrom }\end{array}$ & $\begin{array}{l}\text { The Dynamics of Immigrant Welfare and Labor } \\
\text { Market Behvior }\end{array}$ & $1 / 3$ & 09/01 \\
\hline 361 & $\begin{array}{l}\text { M. C. Berger } \\
\text { J. S. Earle } \\
\text { K. Z. Sabirianova }\end{array}$ & $\begin{array}{l}\text { Worker Training in a Restructuring Economy: } \\
\text { Evidence from the Russian Transition }\end{array}$ & 4 & 09/01 \\
\hline 362 & $\begin{array}{l}\text { J. Angrist } \\
\text { V. Lavy }\end{array}$ & $\begin{array}{l}\text { New Evidence on Classroom Computers and } \\
\text { Pupil Learning }\end{array}$ & 6 & 09/01 \\
\hline 363 & $\begin{array}{l}\text { H. Antecol } \\
\text { D. A. Cobb-Clark } \\
\text { S. J. Trejo }\end{array}$ & $\begin{array}{l}\text { Immigration Policy and the Skills of Immigrants } \\
\text { to Australia, Canada, and the United States }\end{array}$ & 2 & 09/01 \\
\hline 364 & $\begin{array}{l}\text { M. Jäntti } \\
\text { S. P. Jenkins }\end{array}$ & $\begin{array}{l}\text { Examining the Impact of Macro-Economic } \\
\text { Conditions on Income Inequality }\end{array}$ & 3 & 09/01 \\
\hline 365 & $\begin{array}{l}\text { H. S. Nielsen } \\
\text { M. Rosholm } \\
\text { N. Smith } \\
\text { L. Husted }\end{array}$ & $\begin{array}{l}\text { Qualifications, Discrimination, or Assimilation? } \\
\text { An Extended Framework for Analysing } \\
\text { Immigrant Wage Gaps }\end{array}$ & 1 & 09/01 \\
\hline 366 & M. C. Regets & $\begin{array}{l}\text { Research and Policy Issues in High-Skilled } \\
\text { International Migration: A Perspective with Data } \\
\text { from the United States }\end{array}$ & $1 / 5$ & 09/01 \\
\hline 367 & C. Dustmann & $\begin{array}{l}\text { Parental Background, Primary to Secondary } \\
\text { School Transitions, and Wages }\end{array}$ & 5 & 09/01 \\
\hline 368 & J. Angrist & $\begin{array}{l}\text { How Do Sex Ratios Affect Marriage and Labor } \\
\text { Markets? Evidence from America's Second } \\
\text { Generation }\end{array}$ & 5 & 09/01 \\
\hline 369 & A. S. Kalwij & $\begin{array}{l}\text { Individuals' Unemployment Durations over the } \\
\text { Business Cycle }\end{array}$ & 3 & 09/01 \\
\hline 370 & A. S. Kalwij & $\begin{array}{l}\text { Individuals' Unemployment Experiences: } \\
\text { Heterogeneity and Business Cycle Effects }\end{array}$ & 3 & 09/01 \\
\hline 371 & $\begin{array}{l}\text { S. C. Wolter } \\
\text { A. Zbinden }\end{array}$ & $\begin{array}{l}\text { Rates of Return to Education: The View of } \\
\text { Students in Switzerland }\end{array}$ & 5 & 09/01 \\
\hline 372 & $\begin{array}{l}\text { J. Konings } \\
\text { H. Lehmann }\end{array}$ & $\begin{array}{l}\text { Marshall and Labour Demand in Russia: Going } \\
\text { Back to Basics }\end{array}$ & 4 & 09/01 \\
\hline 373 & S. J. Trejo & $\begin{array}{l}\text { Does the Statutory Overtime Premium } \\
\text { Discourage Long Workweeks? }\end{array}$ & 1 & $10 / 01$ \\
\hline 374 & $\begin{array}{l}\text { G. J. van den Berg } \\
\text { B. van der Klaauw }\end{array}$ & $\begin{array}{l}\text { Counseling and Monitoring of Unemployed } \\
\text { Workers: Theory and Evidence from a } \\
\text { Controlled Social Experiment }\end{array}$ & 6 & $0 / 01$ \\
\hline
\end{tabular}

